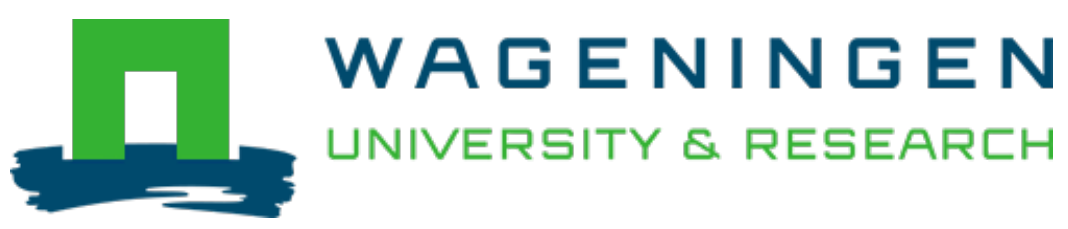

\title{
Reconstruction of ESA CCI satellite-derived soil moisture using an artificial neural network technology
}

\author{
Science of the Total Environment \\ Zhang, Linqi; Liu, Yi; Ren, Liliang; Teuling, Adriaan J.; Zhang, Xiaoxiang et al \\ https://doi.org/10.1016/j.scitotenv.2021.146602
}

This publication is made publicly available in the institutional repository of Wageningen University and Research, under the terms of article $25 \mathrm{fa}$ of the Dutch Copyright Act, also known as the Amendment Taverne. This has been done with explicit consent by the author.

Article 25 fa states that the author of a short scientific work funded either wholly or partially by Dutch public funds is entitled to make that work publicly available for no consideration following a reasonable period of time after the work was first published, provided that clear reference is made to the source of the first publication of the work.

This publication is distributed under The Association of Universities in the Netherlands (VSNU) 'Article $25 \mathrm{fa}$ implementation' project. In this project research outputs of researchers employed by Dutch Universities that comply with the legal requirements of Article $25 \mathrm{fa}$ of the Dutch Copyright Act are distributed online and free of cost or other barriers in institutional repositories. Research outputs are distributed six months after their first online publication in the original published version and with proper attribution to the source of the original publication.

You are permitted to download and use the publication for personal purposes. All rights remain with the author(s) and / or copyright owner(s) of this work. Any use of the publication or parts of it other than authorised under article $25 \mathrm{fa}$ of the Dutch Copyright act is prohibited. Wageningen University \& Research and the author(s) of this publication shall not be held responsible or liable for any damages resulting from your (re)use of this publication.

For questions regarding the public availability of this publication please contact openscience.library@wur.nl 


\section{Reconstruction of ESA CCI satellite-derived soil moisture using an artificial neural network technology}

\section{Linqi Zhang $^{\mathrm{b}}$, Yi Liu ${ }^{\mathrm{a}, \mathrm{b}, *}$, Liliang Ren ${ }^{\mathrm{a}, \mathrm{b}, *}$, Adriaan J. Teuling ${ }^{\mathrm{c}}$, Xiaoxiang Zhang ${ }^{\mathrm{b}}$, Shanhu Jiang ${ }^{\mathrm{a}, \mathrm{b}}$, Xiaoli Yang ${ }^{\mathrm{a}, \mathrm{b}}$, Linyong Wei ${ }^{\mathrm{b}}$, Feng Zhong ${ }^{\mathrm{b}}$, Lihong Zheng ${ }^{\mathrm{b}}$}

a State Key Laboratory of Hydrology-Water Resources and Hydraulic Engineering, Hohai University, Nanjing 210098, China

b College of Hydrology and Water Resources, Hohai University, Nanjing 210098, China

${ }^{\mathrm{c}}$ Hydrology and Quantitative Water Management Group, Wageningen University, Wageningen 6708PB, the Netherlands

\section{H I G H L I G H T S}

- One artificial neural network-based approach for filling spatial gaps of satellite-derived soil moisture was proposed.

- Estimated accuracy of soil moisture presented significant discrepancy under high- and low-density vegetation.

- Machine learning technology displayed competitive advantage in reconstructing soil moisture relative to ordinary kriging.

\section{A R T I C L E I N F O}

\section{Article history:}

Received 17 October 2020

Received in revised form 3 January 2021

Accepted 16 March 2021

Available online 31 March 2021

Editor: Martin Drews

\section{Keywords:}

Soil moisture

ESA CCI

Reconstruction

Artificial neural network

Original kriging

\section{GR A P H I C A L A B S T R A C T}

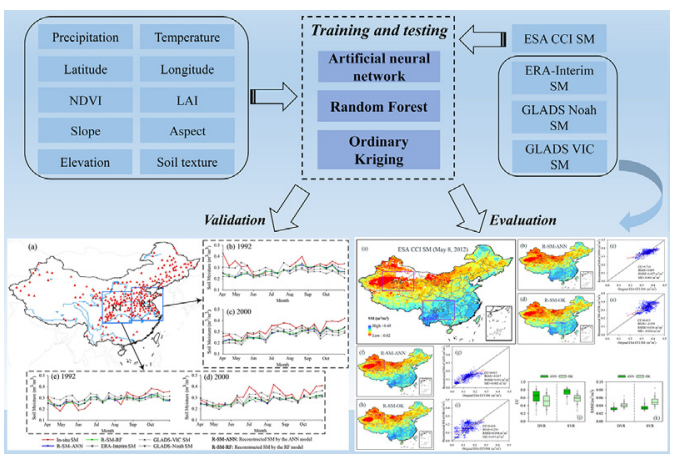

\begin{abstract}
A B S T R A C T
Soil moisture (SM) is a vital variable for controlling water and heat exchange between the atmosphere and land surface. Spatiotemporally continuous satellite-derived SM information is urgently needed for large-scale meteorological and hydrological applications. This study proposes the application of a spatial gap-filling method using an artificial neural network (ANN) to reconstruct missing records of daily surface SM from the Climate Change Initiative program of the European Space Agency (ESA CCI) in the growing seasons of 1982-2015 across China. Ten environmental variables were taken into consideration, including meteorological forcing, geographic and topographic features, vegetation conditions, and soil texture. The ANN-reconstructed SM and RF-reconstructed SM were validated using the ground-based observations and three global reanalysis SM datasets. The gap-filling results by the ANN model were compared to that by the original kriging (OK) model under three simulation scenarios: SM images with removed swaths, varying vegetation densities, and different percentages of data gaps. The results showed that the ANN-reconstructed SM was in good agreement with in-situ SM observations, with the CC more than 0.607 and the RMSE less than $0.074 \mathrm{~m}^{3} / \mathrm{m}^{3}$ over the northwestern and eastern parts of China. Compared with the original ESA CCI SM, the ANN model performed better than the OK model in reconstructing SM with absent swaths and in densely and sparsely vegetated regions. Specifically, the ANN-reconstructed SM provided a higher estimation accuracy in regions with low-density vegetation than in those with high-density vegetation. The weaker performance may due to the complex interactions between surface SM and various environmental variables underneath the dense vegetation. In addition, the ANN model significantly outperformed the OK model by accurately estimating SM when the percentage of data gaps succeeded $40 \%$. Our study is valuable for providing an alternative reference to reconstruct satellite-derived SM and highlights the potential of using the ANN model.
\end{abstract}

(C) 2021 Elsevier B.V. All rights reserved.

\footnotetext{
* Corresponding authors at: State Key Laboratory of Hydrology-Water Resources and Hydraulic Engineering, Hohai University, Nanjing 210098, China.

E-mail addresses: liuyihhdx@126.com (Y. Liu), RLL@hhu.edu.cn (L. Ren).
} 


\section{Introduction}

Soil moisture (SM) has widely been recognized as a key variable in the climate system, given its important role in controlling the exchanges of water, energy, and carbon fluxes between the land surface and atmosphere (Long et al., 2019; Ochsner et al., 2013; Peng et al., 2017; Sheffield and Wood, 2008; Yuan et al., 2015). As a result, SM has been used for a wide range of applications, including climate prediction (Teuling, 2018), drought monitoring (Liu et al., 2020b; Zhang et al., 2019; Wei et al., 2019), flood forecasting (Wanders et al., 2014), and water resource management (Dobriyal et al., 2012). It is also one of the 50 essential climate variables that are considered crucial by the Intergovernmental Panel on Climate Change (IPCC) and United Nations Framework Convention on Climate Change (UNFCCC, Wagner et al., 2012). A long time series of continuous SM data in time and space scales can help us understand meteorological and hydrological processes. Therefore, reliable, accurate, and complete SM information is urgently needed.

As an important environmental variable, SM can be obtained from in-situ measurements, simulated by land surface modeling or retrieved from satellite remote sensing observations (Robock et al., 2000; Dirmeyer et al., 2004; Njoku et al., 2003). Each method has its advantages and limitations. The ground-based measurements have a reliable estimation at the point scale and reflect the temporal variability of the average SM value at a smaller scale (Ngunyen et al., 2017; Wagner et al., 2008). There are many in-situ monitoring networks organized at the national, regional, and global scales, for instance, China-the crop growth and farmland SM database (An et al., 2016), North Americathe North American Soil Moisture Database (NASMD, Quiring et al., 2016), and worldwide-the International Soil Moisture Network (ISMN, Dorigo et al., 2011). Despite these national to global efforts, it is still challenging to obtain spatially-continuous SM data over large regions owing to the limited ground-based measurements. Apart from the ground-based observations, SM can be simulated using land surface modeling. For example, the Global Land Data Assimilation System (GLDAS, Al-Yaari et al., 2014) and Modern-Era Retrospective Analysis for Research and Applications-Land (MERRA-Land) have sufficient spatial coverage, but their estimation accuracy is highly affected by the uncertainties originating from external forcing, model parameterization, and model structure (Raoult et al., 2018). In the last few decades, satellite remote sensing has been deemed an effective and powerful tool for retrieving surface SM (usually depth of $0-5 \mathrm{~cm}$ ) with the development of sensor technologies and retrieval algorithms using active (radar) or passive (radiometer) microwave instruments (Loew et al., 2006; Zeng et al., 2015). Several observation systems use higher C-band and Xband microwave frequencies, such as the Advanced Microwave Scanning Radiometer-Earth Observation System (AMSR-E), Advanced Scatterometer (ASCAT), WindSat, and FengYun-3B. These observation systems are easily influenced by vegetation cover and atmospheric factors (Albergel et al., 2012; Gruhier et al., 2010). Other SM-dedicated satellites (e.g., the Soil Moisture and Ocean Salinity, Soil Moisture Active and Passive) are equipped with a lower L-band radiometer. They are recognized as the most promising satellite-based SM sources owing to the L-band capacity to better penetrate vegetation and image SM. Moreover, the Climate Change Initiative of the European Space Agency (ESA $\mathrm{CCI}$ ) has produced a complete and consistent (temporal coverage more than 30 years) global SM dataset by blending active and passive microwave products, the so-called ESA CCI SM product (Liu et al., 2011). Satellite remote sensing observations provide global coverage as well as near-real-time and consistent SM estimates compared with the traditional in-situ measurements (Barrett et al., 1990; Heumann, 2011). Besides, satellite-derived SM datasets provide higher accuracy than the modeled datasets, particularly where models' inputs have higher uncertainties (Cammalleri et al., 2017). Therefore, microwave remote sensing has significant advantages in providing surface SM estimations over ground-based measurements and model simulations.
Despite the ability of active and passive microwave remote sensing to provide SM data on large scales, gaps in satellite-based SM products are common. These gaps are predominantly caused by satellite orbit changes, radio-frequency interference (RFI), or physical limitations of satellite sensors (Dorigo et al., 2017; Xiao et al., 2016). Fig. 4(c) shows the percentage of data gaps derived from the ESA CCI SM during the growing seasons of 1982-2015. The average percentage of data gaps across China was more than 50\% and reached over $75 \%$ in the western part of Tibet. To reduce the data gaps, Jing et al. (2018) implemented the random forest $(\mathrm{RF})$ regression algorithm to reconstruct the monthly ESA CCI SM at a global scale. They were able to improve the spatial resolution of monthly ESA CCI SM by taking advantage of optical remote sensing products with a high spatial resolution. Llamas et al. (2020) compared and tested three approaches, that is, ordinary kriging (OK), regression kriging (RK), and generalized linear models, to fill the spatial data gaps of ESA CCI SM from January 2000 to September 2012 across the Midwest of USA. The presence of data gaps limits the practical application of the ESA CCI SM product in several fields (e.g., climatic modeling, drought monitoring, water resource management) that require spatially and temporally complete SM datasets.

Several approaches have been used to fill the gaps in satellite-derived datasets. These methods can be classified into four categories: statistical, interpolation, machine learning, and others. Statistical methods (e.g., multiple linear regression, non-linear regression) mainly rely on the linear or non-linear relationship of input and target data. Wang et al. (2012) introduced a three-dimensional method-a penalized least square regression-based on the discrete cosine transform (DCT-PLS) method to utilize the statistical relationship of SM information derived from both time and space to fill data gaps in the global SM datasets. Traditional geostatistical interpolation methods (e.g., inverse distance weighting (IDW), OK) are widely used to fill missing data depending on the spatial pattern of the target variable (Llamas et al., 2020). Machinelearning technologies (e.g., ANN, RF, support vector machine (SVM), Long Short-Term Memory (LSTM)) usually learn complex relationships between input and target variables and simplify the physical processes and calculations. Other methods have been used for filling data gaps of remotely sensed products. For example, Turlapaty et al. (2011) used an improved singular spectral analysis to fill the inherent gaps in the advanced microwave scanning radiometer (AMSR-E) SM dataset. All the methods mentioned above have been widely used for estimating the missing values of various hydrological and climate variables, including precipitation (Coulibaly and Evora, 2007), streamflow (Ng et al., 2009), total water storage (Sun et al., 2020), evapotranspiration (Cui et al., 2020), and air temperature (Schneider, 2001). However, limited studies have been published on filling missing SM values, especially for ANN.

This study proposes a spatial gap-filling method to produce a spatially-complete and temporally-continuous surface SM dataset derived from the ESA CCI product v4.4. Specifically, we used the ANN model to reveal the relationship between the ESA CCI SM and ten environmental variables, including meteorological forcing, geographic and topographic features, vegetation conditions, and soil texture. Section 2 provides a brief description of the study region, data acquisition methods, and processing. The gap-filling methods, evaluation metrics, and general framework are described in Section 3. Section 4 validates the ANN reconstructed SM results against in-situ observation and other SM sources, and compares the performance of this model with that of the RF and OK models. Section 5 discusses the performance of the reconstruction work and the limitation in this study. The main conclusions are given in Section 6.

\section{Study area and data}

\subsection{Study area}

China is located between $3^{\circ} 51^{\prime} \mathrm{N}-53^{\circ} 33^{\prime} \mathrm{N}$ and $73^{\circ} 33^{\prime} \mathrm{E}-135^{\circ} 05^{\prime} \mathrm{E}$, covering an area of approximately $9.6 \times 10^{6} \mathrm{~km}^{2}$ (Fig. 1). Five basic 
terrain types (i.e., plain, plateau, mountain, hill and basin) are presented in this region, with an elevation gradually decreasing from west to east. The vast territory and diverse terrains lead to significant differences in temperature and precipitation (An et al., 2016). Therefore, five climate zones have been identified in China, including cold temperate, temperate, warm temperate, subtropical, and tropical climates.

\subsection{Data acquisition and processing}

\subsubsection{ESA CCI soil moisture (SM)}

The ESA CCI SM product was released by the Climate Change Initiative program of the European Space Agency (http://www.esasoilmosture-cci.org/) and aimed at providing a complete and consistent global SM dataset. The product was generated by combining the satellite-derived SM records from multiple active and passive microwave sensors in a synergistic manner (Liu et al., 2011; Wagner et al., 2012). The ESA CCI SM is updated at regular intervals by introducing a new satellite sensor-based dataset and is modified by users' feedback (Dorigo et al., 2017). Based on the ESA CCI product specification documents, the version of the ESA CCI SM (v4.4) was updated using three active (i.e., AMI-WS, MetOp-A ASCAT, and MetOp-B ASCAT) and seven passive (i.e., SMMR, SSM/I, TMI, AMSR-E, AMSR-2, MIRAS, and WindSat) microwave instruments. Three types of daily products are provided, including merge active, merge passive, and active-passive combined microwave products, covering the period from 1978 to 2015, with a spatial resolution of $0.25^{\circ}$ and in units of $\mathrm{m}^{3} / \mathrm{m}^{3}$. Although the ESA CCI SM provides wide spatiotemporal coverage, data gaps are the major challenge caused by the physical limitations of satellite sensors. This study employed the active-passive combined ESA CCI SM datasets (v4.4) for 1982-2015 to evaluate the performance of ANN method for reconstructing the missing records of satellite-derived data. Given the important role of SM in the growth stages of crops (i.e., emergence, pollination, grain filling), we mainly focused on China's growing season (April-October).

\subsubsection{Global reanalysis $S M$ products}

ERA-Interim is a global atmospheric reanalysis dataset produced by the European Center for Medium-Range Weather Forecast (Dee et al., 2011). This product is based on a sequential data assimilation scheme. ERA-Interim has a spatial resolution of about $80 \mathrm{~km}$ and is available at 00:00, 06:00, 12:00, and 18:00 coordinated universal time (UTC) from 1979 to the present. The volumetric SM data from ERA-Interim are provided for four soil depths (0-7, 7-28, 28-100, and 100-289 cm). GLADS-Noah is the Noah model driven by the Global Land Data
Assimilation System v2.1 (GLDASv2.1), which can be downloaded from the website (https://disc.gsfc.nasa.gov/datasets/). The Noah model was generated jointly by the scientists from the National Aeronautics and Space Administration (NASA) Goddard Space Flight Center (GSFC) and the National Oceanic and Atmospheric Administration (NOAA) National Center for Environmental Prediction (NCEP, Rodell et al., 2004). The variable infiltration capacity (VIC) model-a land surface model-is included in the GLDAS v1 (GLDASv1) product. The SM data from the first soil layer with a depth of $1.75-10 \mathrm{~cm}$ is available from GLADS-VIC. Herein, we collected the daily averaged SM data with a spatial resolution of $0.25^{\circ}$ from the first soil layer $(0-7 \mathrm{~cm})$ from 1982 to 2015. We also used the original GLADS-Noah SM data from the first layer $(0-10 \mathrm{~cm})$ at a resolution of $0.25^{\circ}$. The surface $(0-10 \mathrm{~cm}) \mathrm{SM}$ from GLADS-VIC was resampled from $1^{\circ}$ to $0.25^{\circ}$ in this study.

\subsubsection{In-situ observation SM}

The observed SM data over the whole of China was collected from a crop growth and farmland SM dataset, which was released by the China Meteorological Data Sharing Service System (http://data.cma.cn/). The SM contents were measured at five depths (i.e., 10, 20, 50, 70, and 100 $\mathrm{cm}$ ), with a temporal resolution of ten days and a unit of saturation degree (\%). These ground-based SM from 226 observation sites, spanned from January 1991 to December 2012, were selected out of 778 stations in consideration of the higher spatial and temporal coverage. The spatial distributions of these agricultural stations are shown in Fig. 1. We only employed the top layer $(0-10 \mathrm{~cm}) \mathrm{SM}$ to validate the accuracy of the gap-filling results based on the ANN model. For matching the unit of $\mathrm{SM}$, the degree of saturation (\%) was converted to volumetric SM $\left(\mathrm{m}^{3} /\right.$ $\mathrm{m}^{3}$ ) using the following conversation equations:

$\theta_{v}=s \frac{f}{100}$,

where $\theta_{v}$ denotes the volumetric water content $\left(\mathrm{m}^{3} / \mathrm{m}^{3}\right), s$ represents the degree of saturation (\%), and $f$ is a map of the porosity (Hillel, 1982; An et al., 2016).

\subsubsection{Auxiliary data}

\section{(1) Meteorological forcing}

We employed daily meteorological observations, including precipitation and average temperature, collected between 1982 and 2015
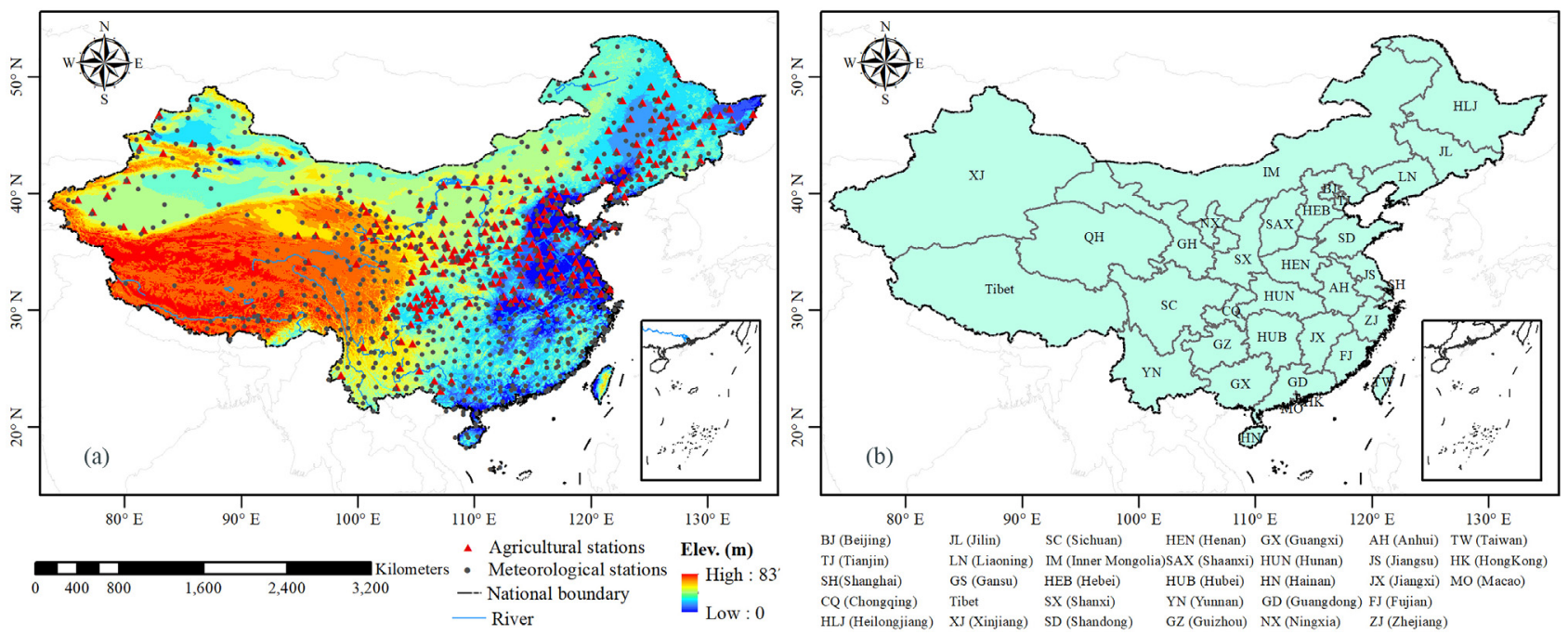

Fig. 1. Spatial distribution of (a) national meteorological and agricultural stations, and (b) administrative divisions in China. 
from the 756 national meteorological stations (Fig. 1). The meteorological data was downloaded from the China Meteorological Administration website (CMA, http://data.cma.cn/). The gridded precipitation and temperature data with a spatial resolution of $0.25^{\circ}$ were generated by the IDW interpolation method with 756 ground-based meteorological gauges.

\section{(2) Geographic and topographic features}

Five types of geographic and topographic data, i.e., central latitude, central longitude, DEM, slope, and aspect, were employed in this study. China's DEM with a spatial resolution of $0.08333^{\circ}$ was obtained from the shutter radar topography mission digital elevation model (SRTM, http://srtm.csi.cgiar.org/). The gridded slope and aspect of the study area were derived from DEM on the geospatial information system platform. All these data were resampled to $0.25^{\circ}$ using the nearest neighbor method.

\section{(3) Vegetation conditions}

\section{a. Normalized difference vegetation index (NDVI)}

The third-generation NDVI (NDVI3g) dataset was released by Global Inventory Modeling and Mapping Studies (GIMMS) and can be retrieved from the NASA Ames ecological forecasting lab (http://ecocast. arc.nasa.gov/da-ta/pub/gimms/3g.v1/). The dataset is the latest version of the GIMMS NDVI product with the longest time series in comparison with other types of NDVI datasets. The new GIMMS NDVI product provides higher quality data for regions in mid-high latitudes when compared with its older version (Zhu et al., 2013). The dataset covers the period from 1982 to 2015 with a temporal resolution of $15 \mathrm{~d}$ and a spatial resolution of $0.0833^{\circ}$. In this study, the NDVI3g dataset was resampled into a spatial resolution of $0.25^{\circ}$ and daily NDVI3g was estimated using the original data with a $15-\mathrm{d}$ temporal resolution. For example, if the NDVI3g value on March 15 was 0.45 , then the values of daily NDVI3g from March 1 to March 15 were assumed to be 0.45 .

\section{b. Leaf area index (LAI)}

The global land surface satellite leaf area index (GLASS LAI) product was generated from the advanced very high-resolution radiometer (AVHRR) LAI (1981-2000) and Moderate Resolution Imaging Spectroradiometer (MODIS) LAI (2000-2015) (Liang et al., 2013). GLASS LAI was released by the Center for Global Change Data Processing and Analysis of Beijing Normal University (http://www.bnu-datacenter. $\mathrm{com} /$ ). It has a spatial resolution of $1 \mathrm{~km}$ and a temporal resolution of 8 d. Compared to other LAI products, GLASS LAI has the advantages of collecting more precise, temporally-continuous, and spatiallycomplete data (Xie et al., 2019). Herein, the daily LAI data from 1982 to 2015 with a spatial resolution of $0.25^{\circ}$ were generated by resampling the original GLASS LAI product. The estimation of daily LAI was similar to that of daily NDVI3g.

\section{(4) Soil texture}

The soil texture used in this study was from the Harmonized World Soil Database (HWSD) v1.1 (Nachtergaele et al., 2009) developed by the Food and Agriculture Organization (FAO) and the International Institute for Applied Systems Analysis (IIASA) in Austria (http://webarchive.iiasa. ac.at). HWSD is a 30 arc-second spatial resolution database that provides soil parameters from the top $(0-30 \mathrm{~cm})$ to the deep (30-100 $\mathrm{cm}$ ) soil profiles for several research fields (Saxton and Rawls, 2006). According to HWSD v1.1, soil texture can be classified into 13 categories, depending on the relative proportion of soil separates (i.e., clay, silt, and sand). In this study, we extracted China's soil texture pixels from HWSD and resampled the data into a $0.25^{\circ}$ spatial resolution using the nearest neighbor method.

\section{Methodology}

\subsection{Artificial neural network}

ANN is a type of machine-learning algorithm based on the biological neural network of the human brain. The back-propagation neural network (BP-NN)-the most commonly used ANN type-is a multilayer supervised learning technology. It has been widely applied because of its strong self-learning ability and robust capacity in resolving non-linear problems (Rumelhart et al., 1986; Wang et al., 2019). This algorithm can achieve the minimum sum of square errors by the steepest gradient descent method and error back-propagation, constantly adjusting the weights and thresholds of neurons (Zhang and $\mathrm{Wu}, 2009$ ). Theoretically, a three-layer neural network can approximate a non-linear function with any precision, as long as enough neurons are equipped.

In this study, three layers (i.e., input, hidden, and output) in BP-NN were used (Fig. 2). Two neurons of each adjacent layer were directly connected with a weighted value, which presented the relational degree between the neurons. Ten neurons in the input layer represented the factors that might affect SM regarding four aspects: geographic and topographic features (i.e., central latitude, central longitude, DEM, slope, and aspect), meteorological forcing (i.e., precipitation and temperature), vegetation conditions (i.e., NDVI and LAI), and soil texture. The number of neurons in the hidden layer was determined using the following empirical formula:

$h=\sqrt{m+n}+\alpha$,

where $h$ denotes the number of hidden neurons; $m$ is the number of input neurons; $n$ is the number of neurons in the output layer; and $\alpha$ is the constant ranging from 1 to 10 . According to Eq. (2), the distribution interval of $h$ is $[\sqrt{11}+1, \sqrt{11}+10]$. Finally, the number of hidden neurons was set to 13 , according to the minimum value of the mean square error (MSE). Similarly, the gradient descent of the momentum method (i.e., traingdm) was chosen as the training method. The learning rate, maximum interaction, and target error were set to 0.01 , 1000 , and 0.001 , respectively. The error function $(E)$ was calculated using the following equations:

$$
\begin{aligned}
& f(x)=[1+\exp (-x)]^{-1}, \\
& y_{k}=f\left(\sum_{j=1}^{n} w_{j k} r_{j}-\theta_{k}\right), \\
& b=f_{0}\left(\sum_{k=1}^{m} w_{k} y_{k}-\theta\right), \\
& E=\frac{1}{2}\left(b-b^{\prime}\right)^{2},
\end{aligned}
$$

where $f(x)$ is the sigmoid function used in the training process between the neuron input and output in the hidden layer; $f_{0}$ is the linear function between the neuron input and output in the output layer; $r_{j}(j=1,2, \ldots, n)$ represents the input data; $w_{j k}(j=1,2, \ldots, n ; k=1,2, \ldots, m)$ represents the connection weights between $j$ th neuron in the input layer and $k$ th neuron in the hidden layer; $\theta_{k}(k=1,2, \ldots, m)$ represents the bias of the $k$ th neuron in the hidden layer; $y_{k}(k=1,2, \ldots, m)$ is the output of $k$ th neuron in the hidden layer; $w_{k}(k=1,2, \ldots, m)$ denotes the weight values between the $k$ th neuron in the hidden layer and the output layer; $\theta$ denotes the neuron bias in the output layer; $b$ is the neuron output in the output layer; and $b^{\prime}$ is the expected output of the network. The connection weights and bias values were modified to minimize $E$ using the following equations:

$w_{k(t-1)}=w_{k(t)}+\eta \delta y_{t}+\alpha\left[w_{k(t)}-w_{k(t-1)}\right]$, 
(a) Training phase

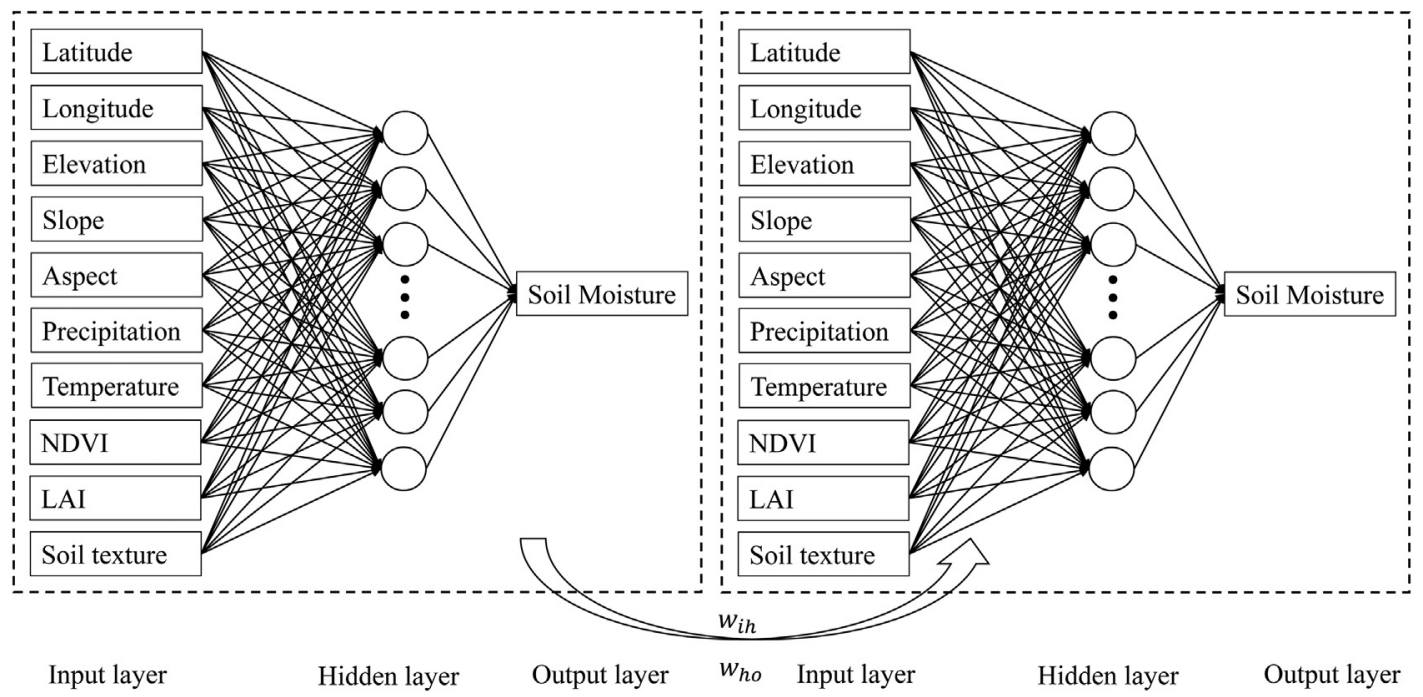

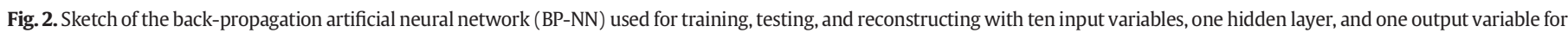
daily soil moisture estimation. $w_{i h}$ and $w_{h o}$ are the weights from the input layer to the hidden layer and the hidden layer to the output layer obtained during the training process.

$w_{j k(t-1)}=w_{j k(t)}+\eta \delta_{k} y_{t}+\alpha\left[w_{j k(t)}-w_{j k(t-1)}\right]$,

$\theta_{(t-1)}=\theta_{(t)}+\eta \delta+\alpha\left[\theta_{(t)}-\theta_{(t-1)}\right]$,

$\theta_{k(t-1)}=\theta_{k(t)}+\eta \delta_{k}+\alpha\left[\theta_{k(t)}-\theta_{k(t-1)}\right]$

where $\eta$ denotes the learning rate; $\alpha$ is the momentum constant; and $t$ represents the iteration. As shown in Fig. 2, weights and thresholds obtained in the training process of neural network were also used for testing the network and reconstructing SM.

\subsection{Radom forest}

Random Forest (RF), first proposed by Breiman (2001) and improved by Cutler et al. (2011), is an ensemble machine-learning technology, which can be popularly applied in classification, regression, and other tasks. This model has some advantages in working with large and high-dimensional datasets and modeling complicated, nonlinear relationships between the predictors and the input variables (Hutengs and Vohland, 2016).

The detailed process of the RF model is as follows: firstly, the RF model divides the input data into multiple decision trees. Each decision tree is made up of a root node, internal nodes, and leaf nodes, which is built from an independently random subset of training data during the process of bootstrap sampling. The left samples in the process act as the out-of-bag (OOB) samples, which will be not used in the model construction but to validate the performance of the constructed model based on the mean squared error (MSE). Then, all the decision trees make up a forest. In the forest, each tree has a predicted value. Finally, the output of the RF method is the average prediction value of all the individual trees for a regression task. For the RF model, two important parameters are required to select by the modeler, i.e., the number of trees and the number of variables (Rahmati et al., 2020). In our study, the number of variables and the number of trees was set to 3 and 1000 , respectively, according to a number of testing results and the stable feature of the $\mathrm{OOB}$ error.

\subsection{Ordinary kriging}

Ordinary Kriging $(\mathrm{OK})$ is one of the most basic and systematically studied kriging methods. It provides a variable estimation at an unobserved location based on a linear weighted average of observations in its neighborhood within a given area using the following equation:

$Z^{*}\left(x_{0}\right)=\sum_{i=1}^{n} \lambda_{i} Z\left(x_{i}\right)$,

where $Z^{*}\left(x_{0}\right)$ is the estimated value at prediction location $x_{0} ; Z\left(x_{i}\right)$ are the observed values from surrounding locations $x_{0}$; $n$ denotes the number of the closest neighboring observations used for the estimation; and $\lambda_{i}$ represents the weight assigned to value $Z\left(x_{i}\right)$, which can be obtained from the unbiased estimation of kriging interpolation and minimum variance, and they sum to 1 , as shown in the equation below:

$\left\{\begin{array}{l}\sum_{\mathrm{i}=1}^{\mathrm{n}} \bar{\gamma}\left(\mathrm{x}_{\mathrm{i}}-\mathrm{x}_{\mathrm{j}}\right) \lambda_{\mathrm{i}}+\mu=\bar{\gamma}\left(\mathrm{x}_{0}-\mathrm{x}_{\mathrm{j}}\right) \quad(\mathrm{j}=1,2, \ldots, \mathrm{n}) \\ \sum_{\mathrm{i}=1}^{\mathrm{n}} \lambda_{\mathrm{i}}=1\end{array}\right.$,

where $\bar{\gamma}\left(x_{i}-x_{j}\right)$ represents the semi-variance between the $i$ th and $j$ th observation points; $\bar{\gamma}\left(x_{0}-x_{j}\right)$ denotes the semi-variance between the prediction point and the $j$ th observation point, both of which can be obtained by the fitted variogram; $\mu$ is the Lagrange multiplier; and $n$ is the number of observation points used in the calculation process. Variogram modeling was used to describe the spatial structure of the variable's distribution in the geostatistical analysis as follows:

$\bar{\gamma}(h)=\frac{1}{2 N(h)} \sum_{i=1}^{N(h)}\left(Z\left(x_{i}\right)-Z\left(x_{i}+h\right)\right)^{2}$,

where $\bar{\gamma}(h)$ is the value of variogram at a particular point; $x_{i}$ and $x_{i}+h$ are the point locations separated by distance $h ; N(h)$ is the number of point pairs separated by distance $h ; Z\left(x_{i}\right)$ and $Z\left(x_{i}+h\right)$ are the observed values of variable $Z$ at the corresponding locations. In this study, we considered the spherical, Gaussian, and exponential models for fitting variograms of daily SM and finally chose the Gaussian model to depict the SM spatial structure variation. Then, we applied the OK method to fill the missing values of ESA CCI SM based on the given model parameters as provided by the experiments in ArcGIS 10.2 .

\subsection{Evaluation metrics}

To quantify the estimated SM deviation of the ANN and OK methods against the original ESA CCI SM, four evaluation metrics were employed: correlation coefficient (CC), root mean squared error (RMSE), relative 
bias (BIAS), and mean error (ME). The ANN performance in the training and testing processes was also evaluated using these statistical metrics. The equations for CC, RMSE, BIAS, and ME are given below:

$C C=\left(\frac{\sum_{i=1}^{n}\left(O_{i}-\bar{O}\right)\left(M_{i}-\bar{M}\right)}{\sqrt{\sum_{i=1}^{n}\left(O_{i}-\bar{O}\right)} \sqrt{\sum_{i=1}^{n}\left(M_{i}-\bar{M}\right)}}\right)$,

$R M S E=\sqrt{\frac{\sum_{i=1}^{n}\left(M_{i}-O_{i}\right)^{2}}{n}}$

$B I A S=\frac{\sum_{i=1}^{n}\left(M_{i}-O_{i}\right)}{\sum_{i=1}^{n} O_{i}}$,

$M E=\frac{1}{n} \sum_{i=1}^{n}\left(M_{i}-O_{i}\right)$,

where $M_{i}$ represents the estimated ESA CCI SM by the ANN, and OK methods in grid $i ; O_{i}$ denotes the original ESA CCI SM in grid $i ; \bar{M}$ and $\bar{O}$ is the average value of $M_{i}$ and $O_{i}$, respectively, from the corresponding data arrays; and $n$ is the number of samples.

\subsection{General framework}

A general flowchart for the ESA CCI SM reconstruction is presented in Fig. 3. We used the ESA CCI SM and ten environmental variables as the forcing data in this study. The ANN, RF, and OK models were utilized to reconstruct the ESA CCI SM. The former two were equipped with extra environmental variables in comparison with the latter using the ESA CCI SM as the input. The process for filling the ESA CCI SM gaps based on the ANN and RF model was as follows. First, we determined SM temporal consistency for approximately 10-day, according to the comparison experiments. Then, we combined a 10-day (consecutive) time series from each dataset in the growing season (April-October) for 1982-2015 into several accumulation datasets. For example, the datasets from April 1 to April 10, 1982, and April 11 to April 20, 1982, were classified into two accumulation datasets, similar to the study by Cui et al. (2016), where they considered a large grid cell $\left(1^{\circ} \times 1^{\circ}\right)$ with all available remote sensing SM pixels within one year. Next, the valid SM pixels from these accumulation datasets ( $~ 80 \%$ of the sample) were used to train the models. The remaining available SM pixels ( $20 \%$ of the sample) were used to test the trained model performance. After that, the missing records of the ESA CCI SM were predicted using the trained models. Finally, the gap-filling results were validated by comparison with the in-situ observations and three global reanalysis SM datasets (i.e., ERA-Interim, GLADS-VIC, and GLADS-Noah).

To evaluate the performance of ANN and OK models for estimating $\mathrm{SM}$, three simulation scenarios were employed for further study. As shown in previous studies, the ANN model is difficult to be trained thoroughly and effectively because of the limited valid values that exist in the original dataset (Yuan et al., 2020). Thus, a relatively complete SM series in space scale with less than $10 \%$ of data gaps were considered herein. The simulation scenarios used are presented below.

(1) Removing swaths scenario. Swaths are normally observed in passive-active retrieved products (e.g., ESA CCI SM) mainly due to the ascending or descending satellite sensors (Mao et al., 2019; Xiao et al., 2016). According to the original ESA CCI SM images, we noted several different swath patterns in the study area. As shown in Fig. 4(a), we selected four swath patterns across the entire study region: swaths I, II, III, and IV.

(2) Vegetation cover scenario. During different vegetation growth periods, soil evaporation can change significantly based on vegetation cover and meteorological conditions. The change of soil evaporation can lead to the variability of SM. Therefore, vegetation cover is an important factor that may lead to changes in surface SM. In our study, we selected two areas of $1250 \times 1250 \mathrm{~km}$ to represent the densely vegetated regions (DVR, see blue rectangles in western China in Fig. 4(b)) and the sparsely vegetated

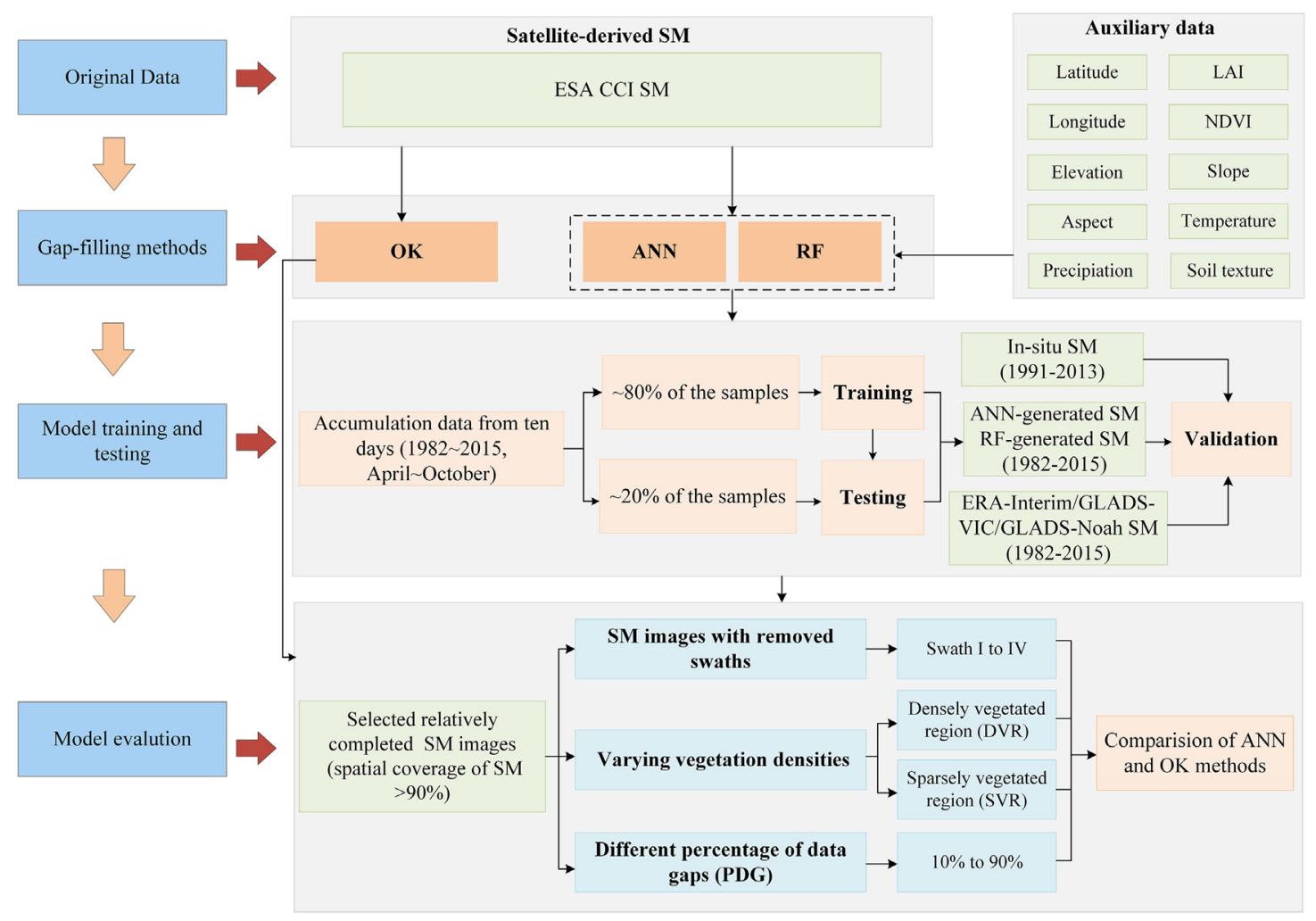

Fig. 3. Flowchart of ESA CCI SM reconstruction and performance evaluation. 

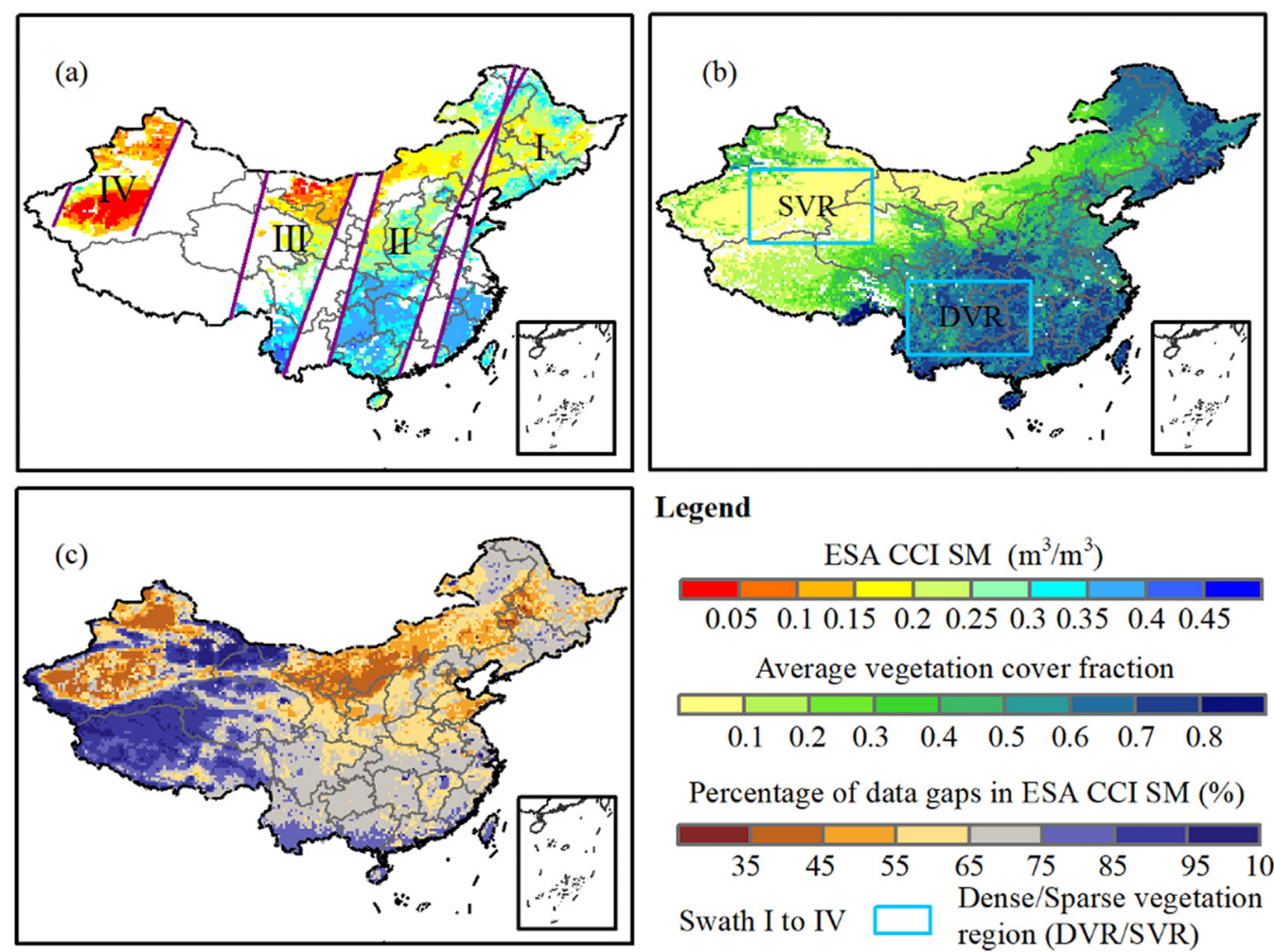

Legend

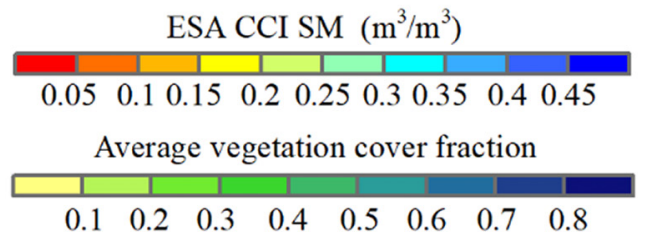

Percentage of data gaps in ESA CCI SM (\%)

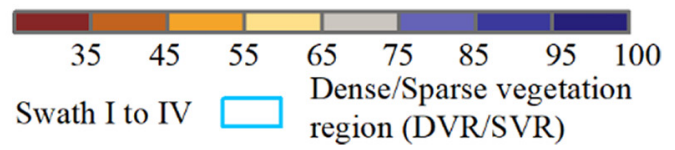

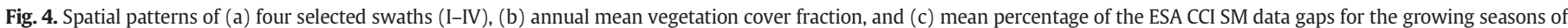

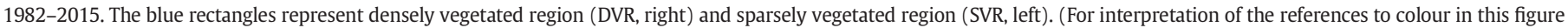
legend, the reader is referred to the web version of this article.)

regions (SVR, see blue rectangles in northern China in Fig. 4(b)) according to the mean vegetation cover conditions in China.

(3) Data gaps scenario. The ANN model requires sufficient data for training neural networks, while the OK model additionally depends on the spatial distribution and self-correlation of valid values in the ESA CCI SM. The estimation results of the ANN and $\mathrm{OK}$ models depend on the percentage of data gaps. The percentage of the ESA CCI SM missing values in the growing seasons between 1982 and 2015 is presented in Fig. 4(c). To analyze the sensitivity of estimation accuracy to the percentage of data gaps, we collected several ESA CCI SM images with different percentages of data gaps (10\%-90\%).

\section{Results}

\subsection{Performance of ANN model in the training and testing phases}

Table 1 shows an overall comparison of the estimated SM against the original ESA CCI SM in the training and testing phases. It can be seen that the ANN model performed well in estimating SM in both phases. From the mean of the statistical indices, CC and RMSE of the simulated SM in the training phase were 0.906 and $0.036 \mathrm{~m}^{3} / \mathrm{m}^{3}$, respectively, while those in the testing phase were 0.902 and $0.037 \mathrm{~m}^{3} / \mathrm{m}^{3}$, respectively.

Table 1

Statistics comparison of estimated SM in the training and testing phases against the original ESA CCI SM.

\begin{tabular}{|c|c|c|c|c|c|c|c|c|}
\hline \multirow[t]{2}{*}{ Index } & \multicolumn{4}{|c|}{ Training phase } & \multicolumn{4}{|c|}{ Testing phase } \\
\hline & $\mathrm{CC}$ & RMSE & BIAS & ME & $\mathrm{CC}$ & RMSE & BIAS & ME \\
\hline Max & 0.948 & 0.047 & 0.003 & 0.001 & 0.946 & 0.049 & 0.017 & 0.003 \\
\hline Mean & 0.906 & 0.036 & 0.000 & 0.000 & 0.902 & 0.037 & 0.000 & 0.000 \\
\hline Min & 0.806 & 0.025 & -0.001 & 0.000 & 0.776 & 0.029 & -0.010 & -0.002 \\
\hline
\end{tabular}

For comparing the performance of the ANN model in different periods, Fig. 5 further displays the box plots of CC and RMSE of the estimated results against the original ESA CCI SM in two phases during the 1980s, 1990s, 2000s, and 2010s. We found that the percentage of data gaps (PDG) during different periods were significantly different. The average PDG during the 1980 s and 1990 s were $89 \%$ and $77 \%$, which were higher than that during the 2000s and 2010s, with the value of $62 \%$ and $37 \%$, respectively. As shown in Fig. 5, the average CC in two phases was generally increased since the 1980 s, though the CC value during the 2000s was slightly decreased compared with that during the 1990s. In terms of the error, the average RMSE in the training and testing phases were significantly reduced from the 1980s to the 2010s. Generally, the ANN model performed well in both phases with higher CC and lower RMSE, even in the circumstances of the lower PDG. All these above results suggest that the trained neural network performed well, and it can be used to fill the ESA CCI SM missing values.

4.2. Validation and comparison of the gap-filling results based on the ANN and RF models

To validate the reliability of the reconstructed SM based on the ANN model, we compared the gap-filling results with SM data derived from five sources: RF-based reconstruction results, ground observations, ERA-Interim, GLADS-VIC, and GLADS-Noah. Table 2 shows the error metrics between reconstructed SM by the ANN and RF model against in-situ observations, and three global reanalysis SM dataset in two selected regions (R1 and R2, see blue rectangle in Fig. 6) that contained enough observation stations. It can be seen that SM could be well reconstructed based on the ANN and RF model against the in-situ observations, with the CC more than 0.607 and the RMSE less than 0.074 in both regions. The gap-filling results also had a good agreement with ERA-Interim SM and GLADS-Noah SM data, with the CC varied between 0.609 and 0.742 and the RMSE ranged from 0.021 to $0.029 \mathrm{~m}^{3} / \mathrm{m}^{3}$. However, the weaker correlations were found when compared with GLADS- 

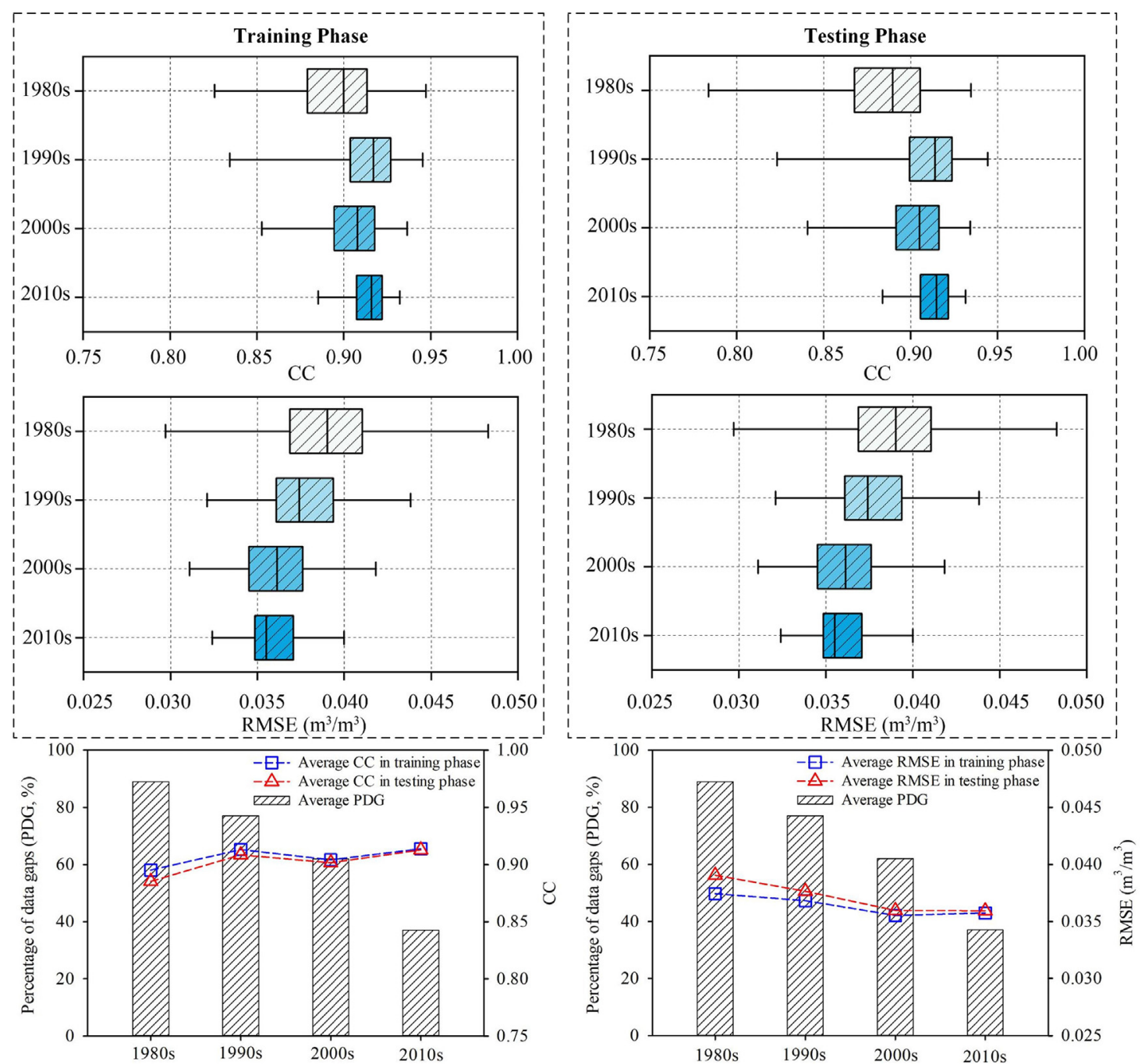

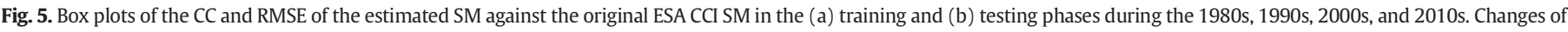

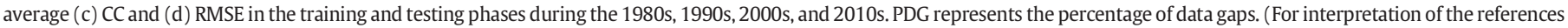
to colour in this figure, the reader is referred to the web version of this article.)

VIC SM. Furthermore, Fig. 6 shows the changes of area-averaged SM in the northwestern (R1) and eastern (R2) parts of China in the growing seasons of 1992 and 2000. We can clearly know that the estimated SM of the ANN model was close to that by the RF model. Both ANN and RF model generally underestimated SM relative to the in-situ observations.

For further evaluating the reconstruction work, we compared the spatial variability of the ANN gap-filled results against RFreconstructed SM, and three global reanalysis SM products. As an example, we presented one SM image with the higher percentage of data

Table 2

Error metrics of the reconstructed SM based on the ANN (RF) model against the ground observations, ERA-Interim, GLADS-VIC and GLADS-Noah, respectively, for the northwestern (R1) and eastern (R2) parts of China during the growing seasons in 1991-2013. CC1 (CC2) is the correlation coefficient and RMSE1(RMSE2) is the root mean squared error over the region of $\mathrm{R} 1(\mathrm{R} 2)$.

\begin{tabular}{|c|c|c|c|c|c|c|c|c|}
\hline & \multicolumn{4}{|c|}{ ANN-reconstructed SM } & \multicolumn{4}{|c|}{ RF-reconstructed SM } \\
\hline & $\mathrm{CC} 1$ & RMSE1 & $\mathrm{CC} 2$ & RMSE2 & CC1 & RMSE1 & $\mathrm{CC} 2$ & RMSE2 \\
\hline In-situ SM & 0.610 & 0.074 & 0.637 & 0.051 & 0.607 & 0.073 & 0.661 & 0.051 \\
\hline $\begin{array}{l}\text { ERA-Interim } \\
\text { SM }\end{array}$ & 0.676 & 0.035 & 0.703 & 0.023 & 0.701 & 0.035 & 0.742 & 0.021 \\
\hline GLADS-VIC SM & 0.311 & 0.049 & 0.388 & 0.043 & 0.323 & 0.048 & 0.413 & 0.042 \\
\hline $\begin{array}{l}\text { GLADS-Noah } \\
\text { SM }\end{array}$ & 0.681 & 0.029 & 0.609 & 0.025 & 0.692 & 0.028 & 0.640 & 0.023 \\
\hline
\end{tabular}

gaps ( $P D G=85 \%$ ), and exhibited the spatial pattern of the original ESA CCI SM, reconstructed SM by the ANN and RF model, ERA-Interim SM, GLADS-VIC SM, and GLADS-Noah SM on April 23, 1982. As shown in Fig. 7(a)-(f), the gap-filled ESA CCI SM based on the ANN and RF model displays a similar spatial distribution. The spatial pattern of the gap-filled ESA CCI SM was also generally in accordance with that of three reanalysis SM data. In addition, area with lower values in the interpolated ESA CCI SM was generally higher than that of the GLADSVIC SM and GLADS-Noah SM, but was lower than that of the ERAInterim SM. Fig. 7(g)-(j) shows the boxplots of CC and RMSE of the ANN-based and RF-based reconstruction results against three analysis SM data. It can be seen that the gap-filled ESA CCI SM using the ANN model presented a good agreement compared with GLADS-Noah SM, with an average CC of 0.838 and an average RMSE of 0.051 , which is better than that relative to the ERA-Interim SM and GLADS-VIC SM, with an average CC of 0.670 and 0.803 , respectively, and an average RMSE of 0.067 and $0.062 \mathrm{~m}^{3} / \mathrm{m}^{3}$, respectively. Compared to the RF model, the ANN model showed a similar performance with an easier algorithm and less afford time on the platform of MATLAB. Based on the above analysis, it can be seen that the ANN-reconstructed ESA CCI SM was reasonable and reliable. In the following paragraph, we would employ three simulation scenarios to further evaluate the performance of the ANN model against one traditional geo-statistic technology (i.e., OK model) for SM estimation in a thorough and analytic manner. 


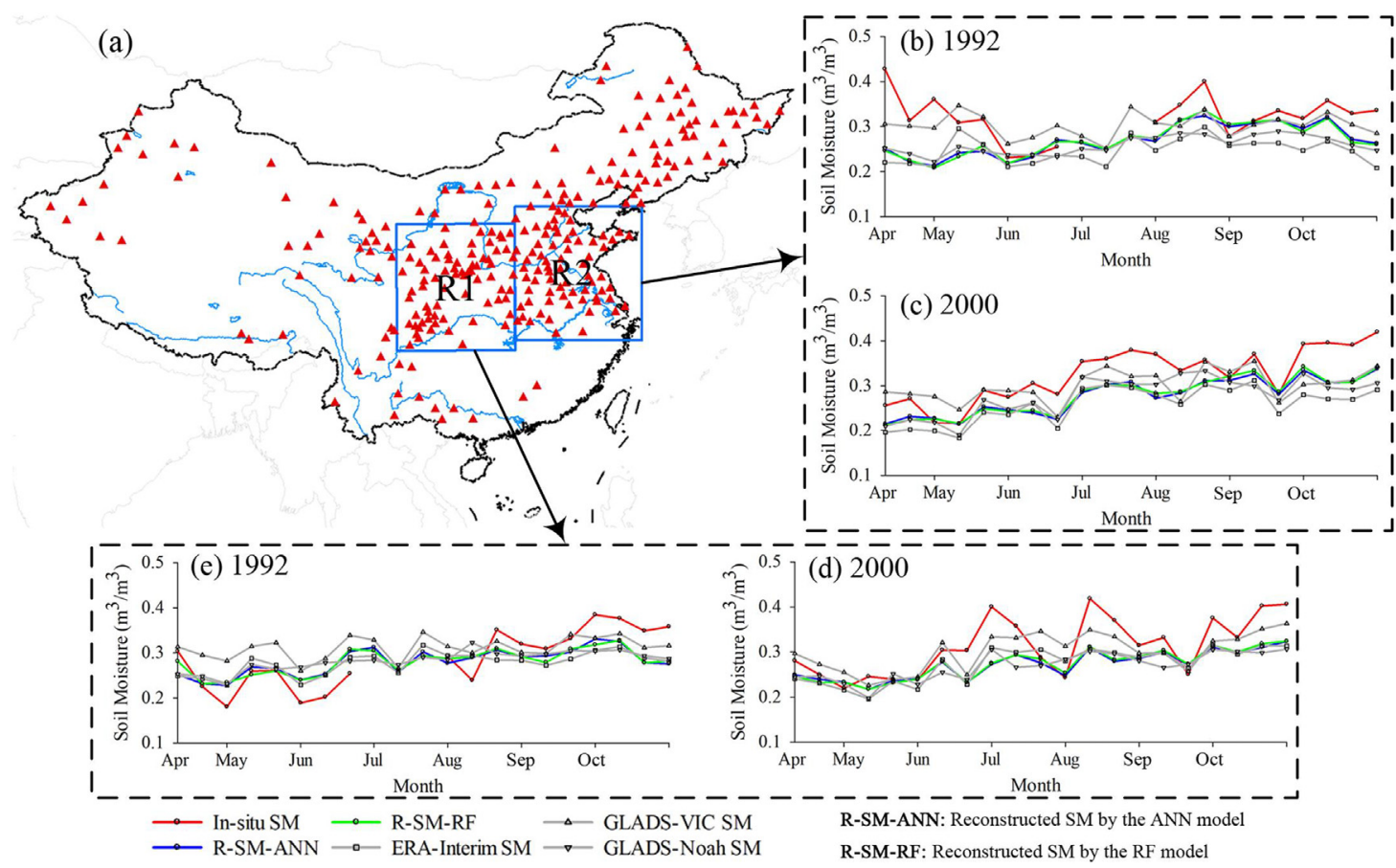

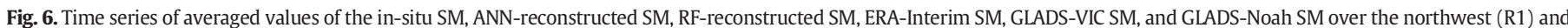
eastern (R2) parts of China during the growing seasons in 1992 and 2000.
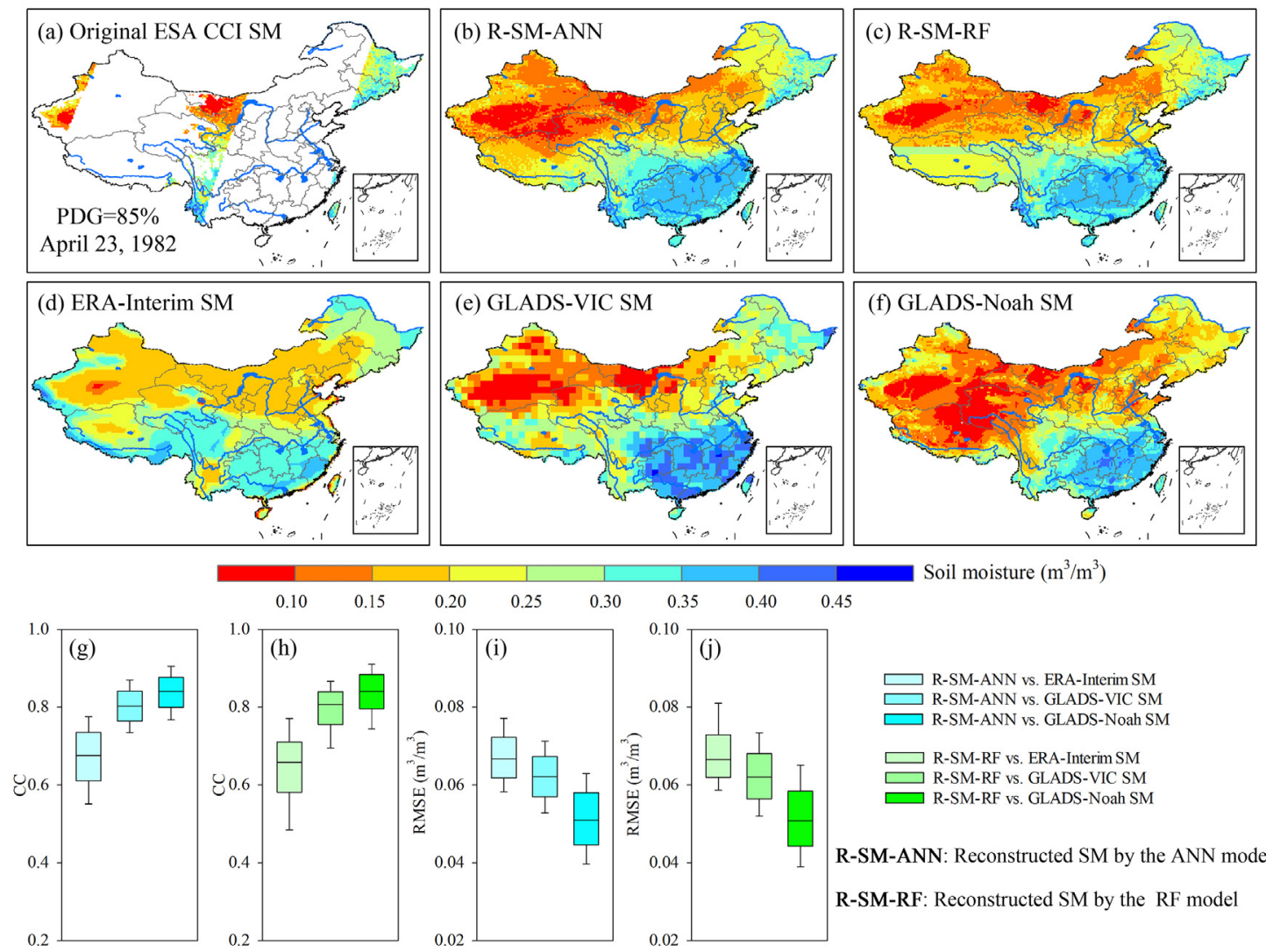

Soil moisture $\left(\mathrm{m}^{3} / \mathrm{m}^{3}\right)$

\subsection{5}

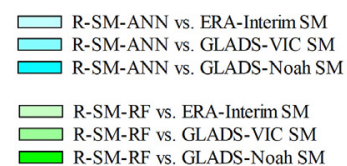

R-SM-RF vs. GLADS-VIC SM

R-SM-ANN: Reconstructed SM by the ANN model

R-SM-RF: Reconstructed SM by the RF model

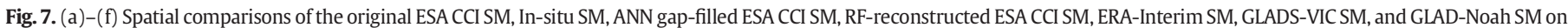

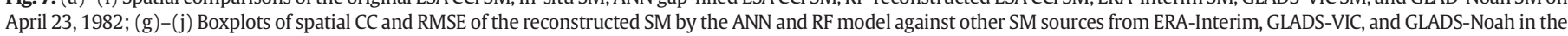
growing seasons (April-October) of 1982-2015. PDG is the percentage of data gaps. 


\subsection{Performance of ANN and OK models for estimating SM with removed} swaths

We took one ESA CCI SM image with the lowest PDG as an example (Fig. 8(a)-(k)) and compared the performance of the ANN and OK models for reconstructing SM using four types of swaths (I, II, III, and IV) removed from the selected ESA CCI SM images on May 8, 2012. The spatial pattern of the ANN reconstructed SM was consistent with the original ESA CCI SM (Fig. 8(b), (f), (j), and (n)). The scatters were well distributed on two sides of the 1:1 line (Fig. 8(c), (g), (k), and (o)), with the CC ranging from 0.852 to 0.947 and the RMSE ranging from 0.032 to $0.035 \mathrm{~m}^{3} / \mathrm{m}^{3}$. Although the spatial distribution of the reconstructed SM using the OK model was generally consistent with the original ESA CCI SM (Fig. 8(e), (i), and (m)), there was a significant discrepancy when a swath IV was removed from the original data (Fig. 8 (p)), with a CC of 0.344 and a RMSE of $0.077 \mathrm{~m}^{3} / \mathrm{m}^{3}$.

For the selected ESA CCI SM images, we constructed the CC and RMSE boxplots of the reconstructed SM by removing swaths I-IV against the original ESA CCI SM (Fig. 8(r) and (s)). As shown, the ANN reconstructed SM was in good agreement with the original ESA CCI $\mathrm{SM}$, with the average CC varied from 0.801 to 0.911 and the average RMSE ranged from 0.035 to $0.037 \mathrm{~m}^{3} / \mathrm{m}^{3}$. In terms of the OK model, we found a certain relationship between the estimation accuracy and the swath location in this study. For example, the OK model performed significantly better in reconstructing missing SM values of swaths I, II, and III than that of swath IV. Overall, compared with the OK model, the ANN model provided a higher accuracy for reconstructing SM independent of the swath's location.
4.4. Overall performance of ANN and OK models in densely and sparsely vegetated areas

Fig. 9 (a)-(i) compare the reconstructed SM of the ANN and OK models against the original ESA CCI SM in the DVR and SVR on May 8, 2012. The spatial pattern of the estimated SM of the ANN model and the original ESA CCI SM were consistent (Fig. 9(b), (c), (f), and (g)). The overall CC, RMSE, BIAS, and ME of the estimated SM using the ANN method in the DVR (SVR) equaled $0.718(0.813), 0.027 \mathrm{~m}^{3} / \mathrm{m}^{3}$ $\left(0.031 \mathrm{~m}^{3} / \mathrm{m}^{3}\right), 0.003(-0.017)$, and $0.001 \mathrm{~m}^{3} / \mathrm{m}^{3}\left(-0.002 \mathrm{~m}^{3} / \mathrm{m}^{3}\right)$, respectively. Compared with the ANN reconstructed SM, the OK model showed an inconsistent spatial pattern with the original ESA CCI SM: SM in eastern Guizhou and northern Guangxi provinces was underestimated (Fig. 9(d)), whereas it was overestimated in southern Tibet (Fig. 9(h)). The scatterplots constructed for the OK estimated SM and the original ESA CCI SM (Fig. 9(e) and (i)) show that the overall CC, RMSE, BIAS, and ME in the DVR and SVR equaled 0.613 and 0.610 , 0.036 and $0.058 \mathrm{~m}^{3} / \mathrm{m}^{3},-0.039$ and 0.256 , and -0.014 and $0.033 \mathrm{~m}^{3}$ / $\mathrm{m}^{3}$, respectively. In addition, the estimated SM values of the ANN and OK models at high SM values were underestimated, but they were overestimated at low values of SM.

Fig. 9(j) and (k) further display the performance of the reconstructed SM based on the ANN and OK models against the original ESA CCI SM for the selected ESA CCI SM images in the DVR and SVR. The estimated SM of the ANN model correlated well with the original ESA CCI SM in the densely and sparsely vegetated areas of southern China, with an average CC of 0.636 and 0.741 and an average RMSE of 0.032 and $0.036 \mathrm{~m}^{3} / \mathrm{m}^{3}$, respectively. The estimated SM of the OK model showed
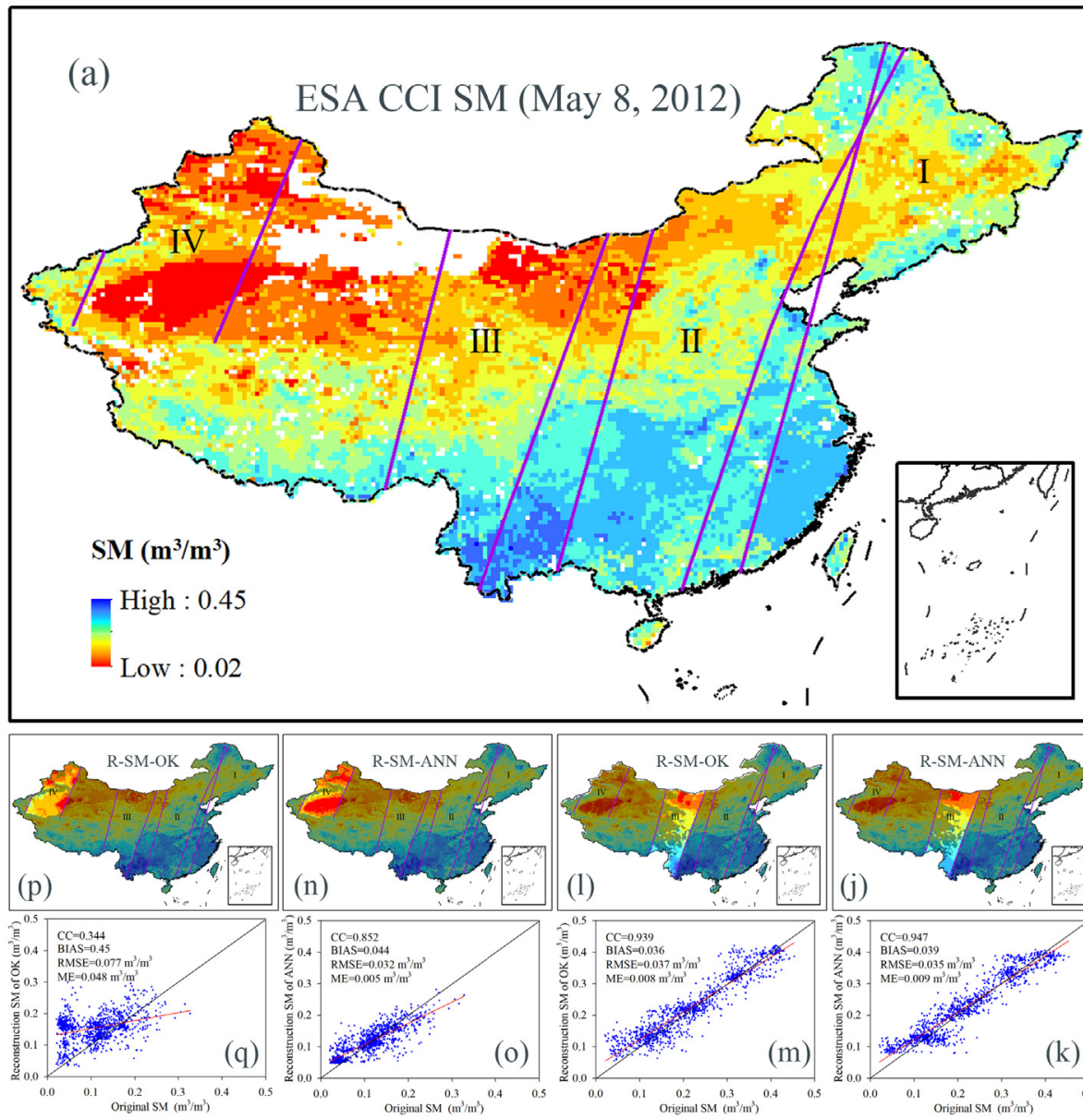
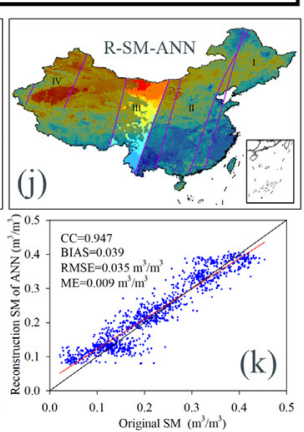
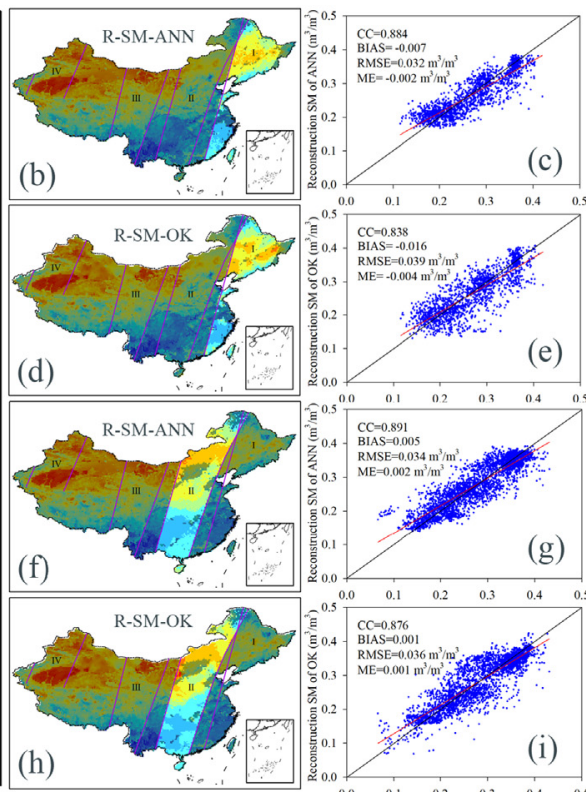

(c)

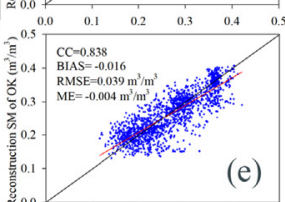

(e)
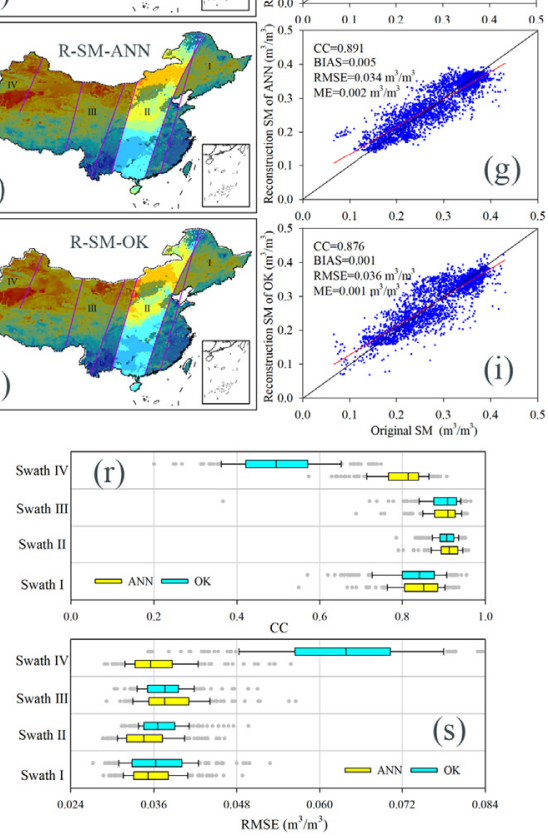

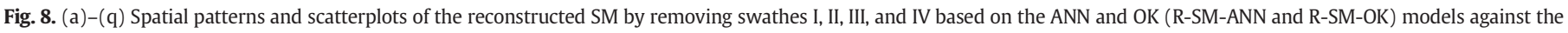

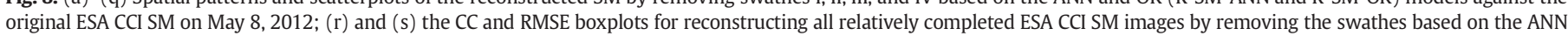
and OK models relative to the original ESA CCI SM. 

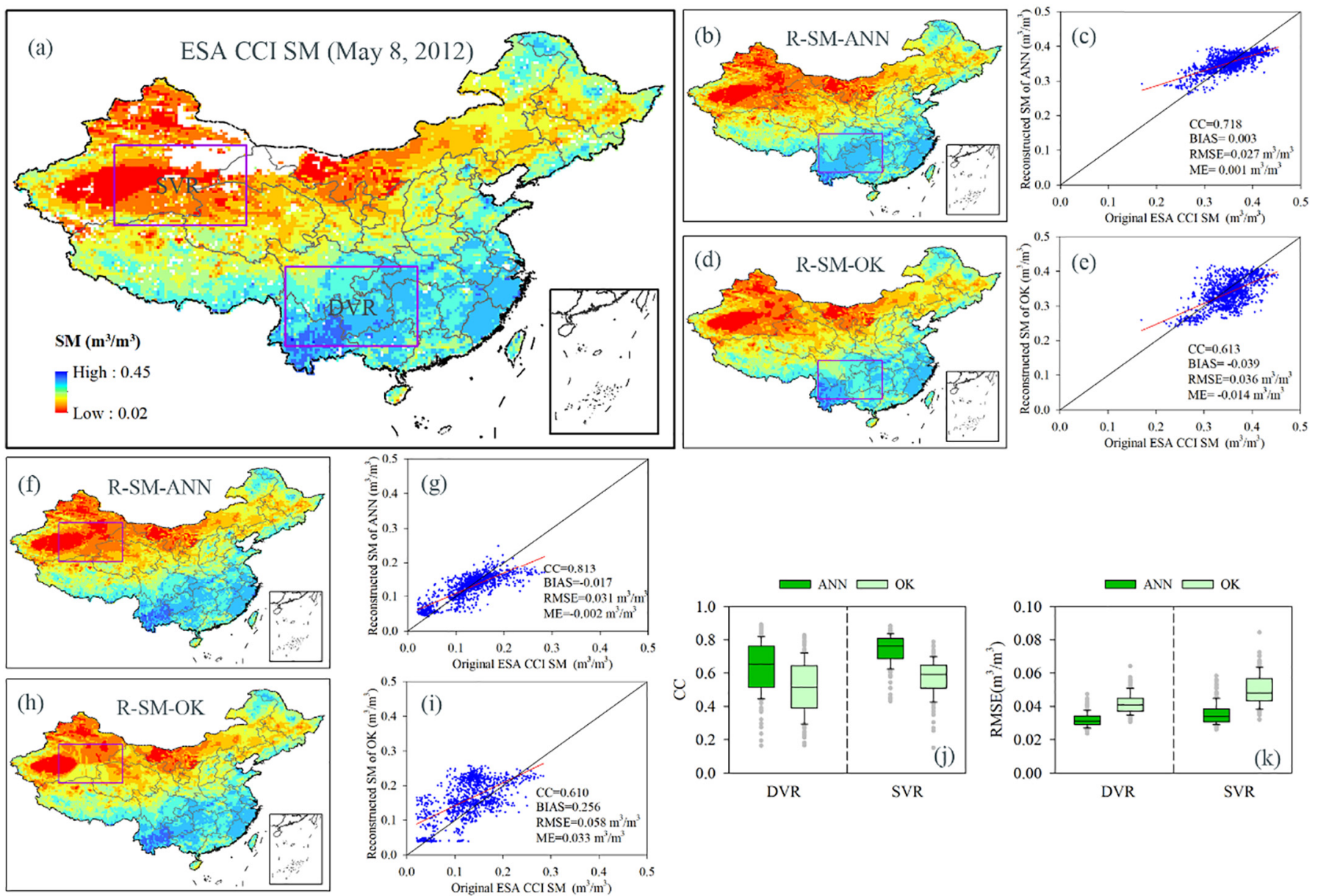

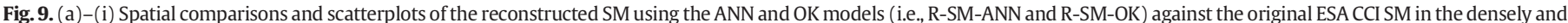

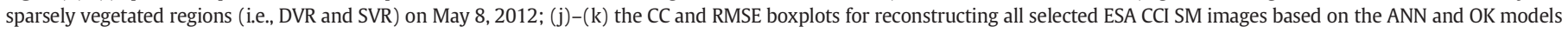
relative to the original ESA CCI SM in the densely and sparsely vegetated areas.

a relatively weaker correlations relative to the original ESA CCI SM in two regions, with an average CC of 0.513 and 0.574 and an average RMSE of 0.042 and $0.050 \mathrm{~m}^{3} / \mathrm{m}^{3}$. The estimated SM of the ANN model in the SVR was more precise than that of the OK model in the DVR. We also noted that the reconstructed SM of the ANN model performed better in the SVR than in the DVR. The average CC and RMSE of the former were determined to be 0.741 and $0.035 \mathrm{~m}^{3} / \mathrm{m}^{3}$, respectively, and those of the latter constituted 0.636 and $0.032 \mathrm{~m}^{3} / \mathrm{m}^{3}$, respectively. In general, the ANN model performed better than the OK model in reconstructing SM in both the DVR and SVR. Moreover, ANN provided a better estimation accuracy of SM in the sparsely vegetated areas than in the densely vegetated ones.

\subsection{Sensitivity analysis of models' simulation accuracy to the percentage of data gaps}

We analyzed the sensitivity of the estimation accuracy of the ANN and OK models to the PDG by comparing the performance of these models. We reconstructed SM using the ANN and OK models by removing different percentages (10\%-90\%) of a given SM image on May 8, 2012 (Fig. 10). The spatial pattern of the original ESA CCI SM was highly consistent with the reconstructed SM of the ANN model for different PDG. In contrast, the spatial distribution of the OK estimated SM was very different from the original ESA CCI SM, and the spatial consistency was significantly improved with a decrease in the PDG. To further show the dynamic changes between the gap-filling accuracy and PDG, we prepared the average CC and RMSE plots of the reconstructed SM based on the selected ESA CCI SM images (Fig. 10(ac) and (ad)). The results showed that the ANN model provided a high estimation accuracy, with the average $\mathrm{CC}$ ranging from 0.811 to 0.923 , and the average RMSE ranging from 0.036 to $0.045 \mathrm{~m}^{3} / \mathrm{m}^{3}$. On the other hand, the SM estimation accuracy of the OK model increased with decreasing data gaps, with the average CC rising from 0.738 to 0.932 , and the average RMSE decreasing from 0.062 to $0.035 \mathrm{~m}^{3} / \mathrm{m}^{3}$. A lower PDG did not signify a higher SM estimation accuracy against the original ESA CCI SM. Moreover, the ANN model displayed a significant advantage over the OK model in rebuilding SM when the PDG succeeded $40 \%$. The average CC and RMSE of the ANN model were 0.904 and $0.037 \mathrm{~m}^{3} / \mathrm{m}^{3}$, respectively, which showed better performance than the OK model, with an average CC and RMSE of 0.836 and $0.048 \mathrm{~m}^{3} / \mathrm{m}^{3}$, respectively. The ANN model performance was slightly weaker than that of the OK model when the PDG was less than $40 \%$. Overall, the ANN model showed a better ability for reconstructing SM, especially when the PDG was over $40 \%$.

\section{Discussion}

In this study, we applied the ANN model to reconstruct missing values of the ESA CCI SM and generate spatially-complete and temporally-continuous satellite-derived SM. The presented method mostly depends on the non-linear relationship between the surface SM and related environmental variables (e.g., NDVI, precipitation). The interpolated results were verified with three global reanalysis datasets (i.e., GLADS-Noah, GLADS-VIC, ERA-Interim) and exhibited good spatial consistency. Compared with the traditional geostatistical method (i.e., OK), the ANN model showed better performance when reconstructing SM with absent swaths. In the DVR and SVR of China, 


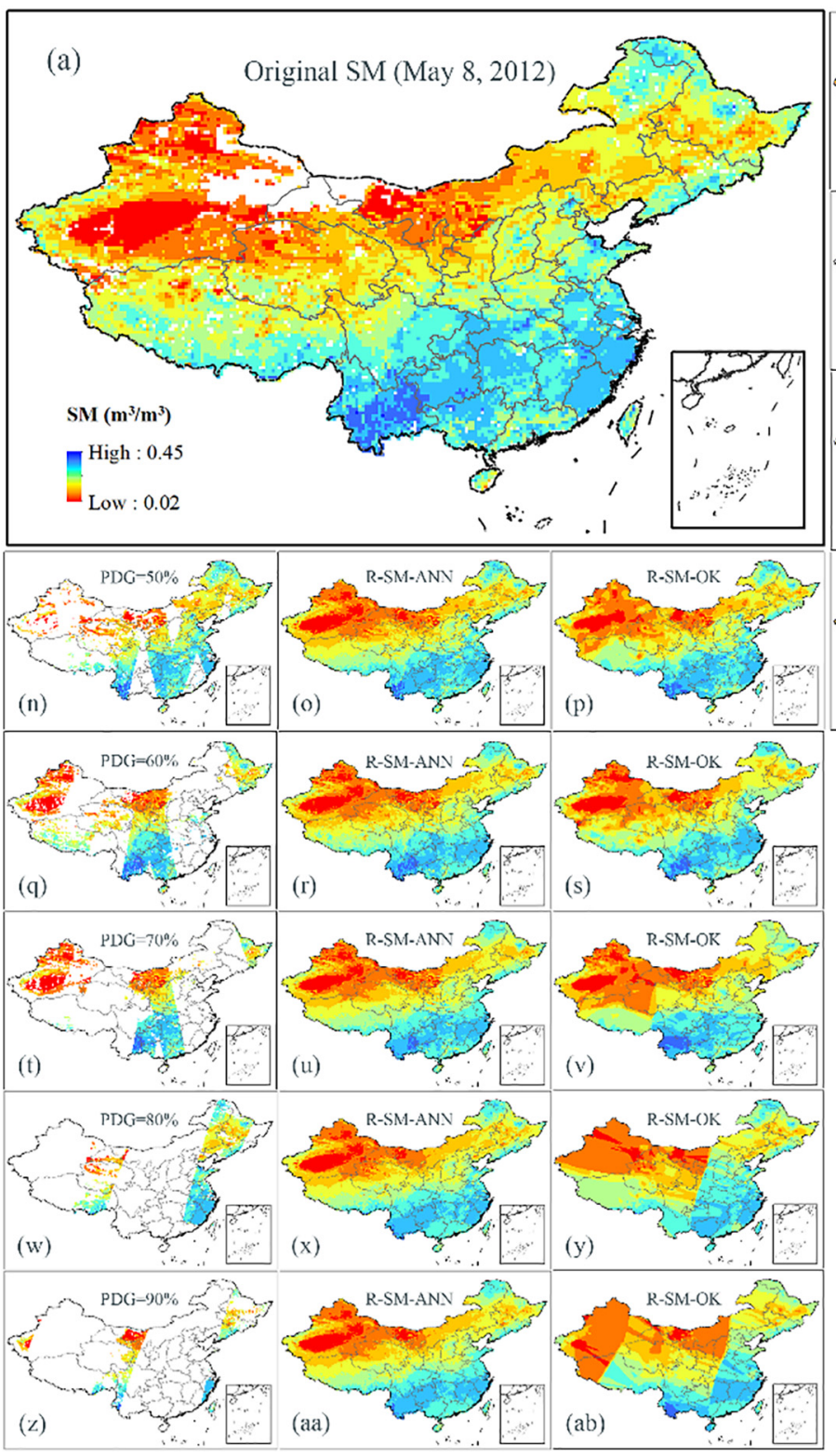

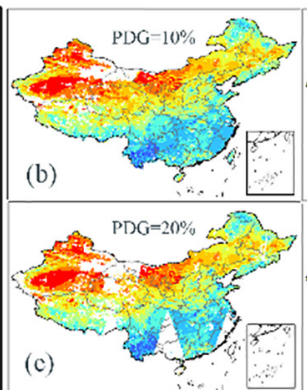
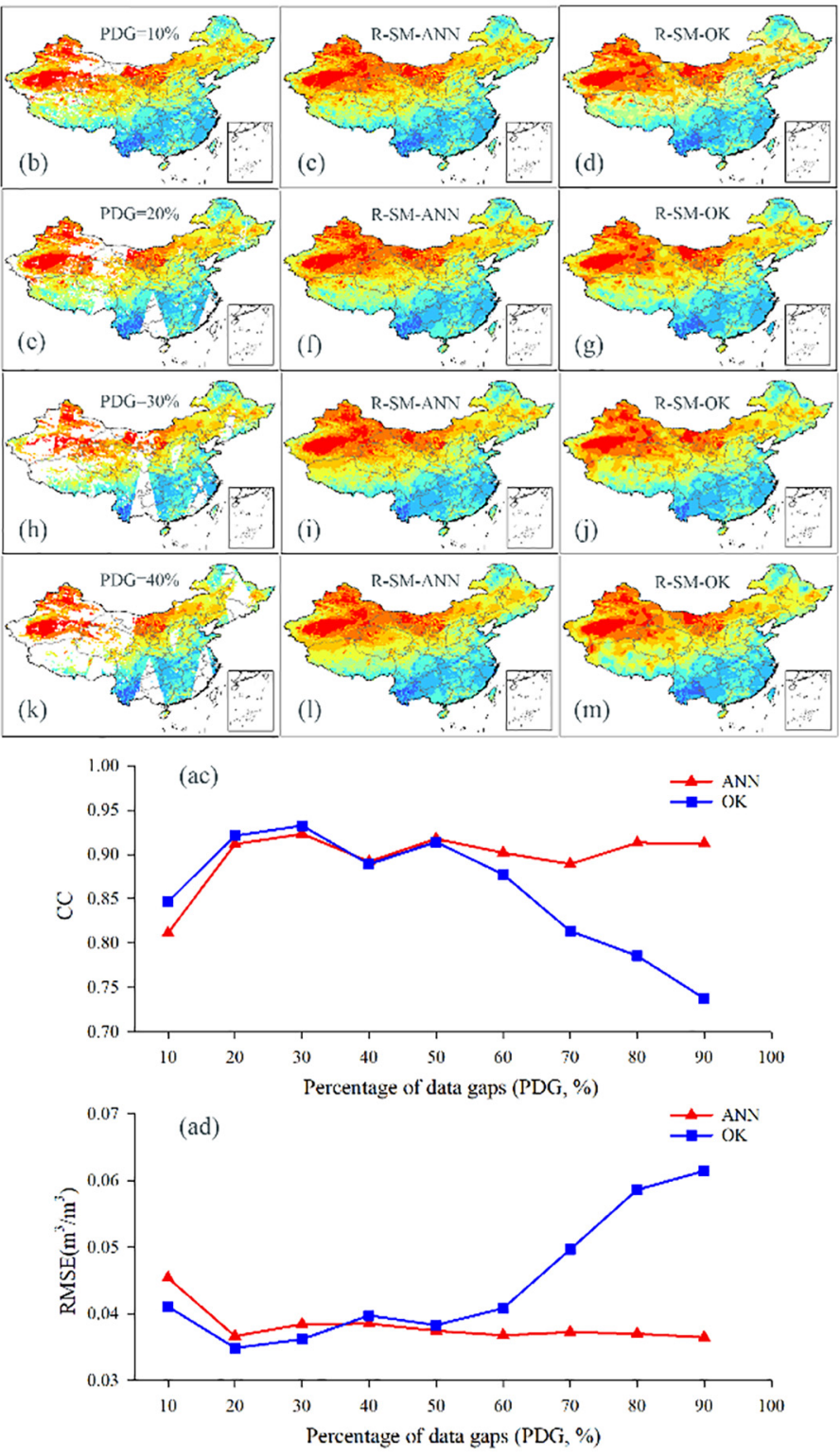

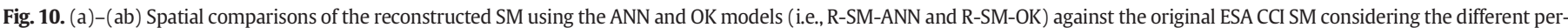
centages of data gaps (PDG) on May 8, 2012; (ac)-(ad) changes in the SM estimation accuracy using the ANN and OK models according to the percentage of data gaps (10\%-90\%).

the ANN model performed better than the OK method. ANN provided better estimation accuracy in the SVR than in the DVR. In addition, the estimation accuracy of the ANN model was less sensitive to the PDG than that of the OK model. Specifically, the ANN model presented significant advantages over the OK model as the PDG succeeded $40 \%$. However, there are three issues related to our study that need further discussion: (1) model performance when reconstructing SM with removed swaths, (2) influence of vegetation cover on model simulation accuracy, and (3) advantages and limitations of the proposed method.

\subsection{Models' performance in reconstructing SM with removed swaths}

Swaths are commonly observed in satellite-derived SM products. The swaths are mostly attributed to the ascending or descending satellite sensors. They also appear due to the physical limitations of microwave remote sensing in providing accurate information under snow/ ice cover, frozen soil, and dense vegetation (Dorigo et al., 2017; Xiao et al., 2016). The missing swaths significantly reduce the spatial coverage of remotely sensed SM and severely restrict its wide application in the fields of hydrology, ecology, and agriculture. Among the published papers on gap-filling of satellite-derived SM, very few studies have concentrated on the capability of interpolated methods in reconstructing SM with absent swaths. Herein, we compared the performance of the ANN and OK models for estimating SM with removed swaths, and the ANN model provided a higher estimation accuracy compared to the original ESA CCI SM. This may be related to the algorithms used in the models. The ANN model was able to simulate SM by taking into consideration several related environmental information, while the OK model merely depended on valid pixels around missing SM values.

\subsection{Influence of vegetation coverage on model simulation accuracy}

We compared the performance of the ANN and OK models in the DVR and SVR of China (Fig. 8). The ANN model performed better than the $\mathrm{OK}$ model in both vegetation modes. This may be related to the ten environmental variables that were considered in the ANN model. For example, NDVI was identified as an essential variable that could reflect vegetation status (Park et al., 2017), and precipitation was the key 
factor that led to changes in surface SM (Long et al., 2019). The OK model only depended on the spatial pattern and autocorrelation of valid ESA CCI SM pixels (Liu et al., 2006; Llamas et al., 2020). Similar results were reported by Ford and Quiring (2014). They found that the accuracy of ANN was significantly higher than that of the OK method, although their study focused on the temporal interpolation of daily SM data. Furthermore, our study results showed that the ANN model provided a better SM estimation accuracy in the sparsely vegetated areas compared with the densely vegetated ones. This might be caused by the extremely complex interaction between the surface SM and vegetation. During different vegetation growth periods, soil evaporation varies greatly under various vegetation coverage with different root depths. The variability of soil evaporation can lead to changes in surface SM (Chen et al., 2007; Fan et al., 2015; Pollen-Bankhead and Simon, 2010). In this study, due to the relatively simple vegetation type and negligible difference in root depth, it was easier for the ANN model to describe the non-linear relationship between SM and related environmental variables and obtain higher estimation accuracy in regions with low-density vegetation than in those with high-density vegetation.

\subsection{Dependence of models' performance on the quality of environment data}

The ANN model used in this study made use of several environment variables. It is worth mentioning that the model's performance would significantly depend on the quality of these environment data. Generally, the precision, respective feature, and sufficient amount of environmental data can provide the high accuracy of the SM estimation. Firstly, the precision of environmental data can directly affect SM estimation accuracy. These environmental data with the quality control could avoid inferior samples (Liu et al., 2020a). Secondly, representative samples can effectively reflect the spatial variability of SM in a given region. However, it is difficult to select typical samples to train the ANN model, thus, randomly selected samples in these environmental data might be the more reliable choice (Mariethoz et al., 2012). The randomization of samples and variables would greatly alleviate the problems of overfitting and sensitivity (Long et al., 2019). Thirdly, the performance of ANN algorithm can be very sensitive to the size of training samples and testing samples. In other words, the more training samples that are available, the better the model fits the data. (Xing et al., 2017; Abbaszadeh et al., 2019). A large number of samples could also have the ability to reflect a whole various characteristic of a dataset (Liu et al., 2020a). In a word, the samples' precision, the respective feature and the amount of available sample, would affect SM reconstruction results. Three aspects need to be considered when we applied the ANN model to reconstruct missing records of satellite data.

\subsection{Comparison with other methods and results in previous literature}

To maximize the advantages of satellite-derived data, many approaches have been used to fill the missing records, including linear regression, geo-statistics, and machine learning methods. These studies had similar measures to estimate the vital variable mainly depend on available remotely sensed data and related environment variables. However, two aspects were different: one is the selection of input variables, the other is the perspective of model evaluation. Table 3 shows the different auxiliary data used in some of the previous studies. For instance, Llamas et al. (2020) employed precipitation and minimum temperature to link the relationship with ESA CCI SM. Liu et al., 2020a applied several environment variables, namely, NDVI and four types of land surface temperature (LST) to reconstruct SM based on the RF model in Oklahoma, USA. In our study, given the complex underlying and diverse meteorological conditions, we chose more auxiliary variables relative to previous researches, as shown in Table 3. Especially, the slope, aspect, and soil texture of China were also employed. With respect to model evaluation, the previous studies mainly focused on the comparison of the entire time series of soil moisture (Cui et al., 2016;
Long et al., 2019). While, this study implemented the evaluation between the ANN and OK model under three simulation scenarios: removing swaths scenario, varying vegetation densities scenario, and different percentages of data gaps scenario. Firstly, the swaths are common issues for satellite-derived soil moisture data. Secondly, vegetation coverage is one of the important variables to affect the dynamic changes of soil moisture. Thirdly, the estimation accuracy of the ANN model is sensitive to the percentage of data gaps. Compared to the former studies, this study concentrated on some practice problems when conducting SM gap-filling work. Comparing with the performance of the ANN model in previous studies, our approach has a good estimation accuracy of $\mathrm{SM}$, with the CC more than 0.607 and the RMSE less than $0.074 \mathrm{~m}^{3} / \mathrm{m}^{3}$ against the in-situ observations over the northwest and east of China. This correlation result was generally comparable to other researches over the Tibetan Plateau (e.g., the minimum CC value is 0.56 and the highest RMSE value is $0.1 \mathrm{~m}^{3} / \mathrm{m}^{3}$ by Cui et al., 2016).

\subsection{Advantages and limitation of this study}

The ANN model combined with several input variables, particularly the ESA CCI SM and multiple surface SM background fields, was successfully employed to generate a spatiotemporally continuous $0.25^{\circ} \times 0.25^{\circ}$ SM product. The ANN gap-filled SM and the RF-reconstructed results were compared and validated against the in-situ observations and three global reanalysis SM products. The performance of the ANN model was also thoroughly evaluated with that of the OK model under three simulation scenarios. As presented herein, the improved dataset could be applied in several fields (e.g., drought monitoring, water resources management) that require continuous SM information over large areas. Moreover, our work provides an alternative reference for filling the gaps in any remotely sensed SM dataset and highlights the potential of ANN in reconstructing missing SM values. In contrast to previous studies (Ford and Quiring, 2014; Long et al., 2019; Mao et al., 2019), our study employed three scenarios of simulation experiments to evaluate the performance of the ANN and OK models for SM estimation in a thorough and analytic manner. However, some limitations of this study are as follows: (1) the results may be affected by the discrepancy of grid-based ESA CCI SM data and point-based in-situ SM data; (2) the accuracy difference of the gap-filled ESA CCI SM against these reanalysis SM may due to different observation depths of SM derived from different datasets; (3) the error of satellite remote sensing may have some influence on the consistency of ESA CCI SM data and in-situ SM observations.

\section{Conclusions}

We proposed a new gap-filling method for missing values of ESA CCI SM based on the ANN model. We were able to generate spatiallycomplete and diurnally-continuous $0.25^{\circ} \times 0.25^{\circ}$ ESA CCI SM by integrating the ESA CCI SM and related environmental variables, including meteorological forcing (i.e., precipitation and temperature), geographic location (i.e., central latitude and longitude), topographic features (i.e., DEM, slope, and aspect), land cover patterns (i.e., NDVI and LAI), and soil texture. The gap-filled ESA CCI SM based on different data combinations showed spatial consistency with the global reanalysis SM derived from GLADS-Noah, GLADS-VIC, and ERA-Interim, reflecting consistent spatial variability in surface SM. Compared with the OK model, the ANN model effectively reconstructed the satellite-derived SM and displayed significant advantages in the three simulation scenarios. The major conclusions are as follows:

(1) The ANN model performed well for estimating SM against the original ESA CCI SM in the training and testing periods. The average CC and RMSE of the ANN model in the training period were 0.906 and $0.036 \mathrm{~m}^{3} / \mathrm{m}^{3}$, respectively, while those in the testing period equaled 0.902 and $0.037 \mathrm{~m}^{3} / \mathrm{m}^{3}$, respectively. The ESA 
Table 3

Comparison of reconstruction variable and auxiliary variables in some of the previous studies.

\begin{tabular}{|c|c|c|c|c|}
\hline Model & Study area & Reconstruction variable & Auxiliary variables ${ }^{\mathrm{a}}$ & Reference \\
\hline MLR, RK, OK & Midwest of the USA & ESA CCI SM & PRE, TEM $_{\text {min }}$ & Llamas et al. (2020) \\
\hline RF, Tri & Oklahoma, USA & ESA CCI SM & NDVI, LST, daytime LST, nighttime LST, daily average LST, diurnal LST & Liu et al., (2020a) \\
\hline ANN & TP, China & FY-3B SM & Snowcover, LST, NDVI, Albeo, DEM, Lat, Lon, DOY & Cui et al. (2016) \\
\hline ANN & China & ESA CCI SM & PRE, TEM, NDVI, LAI, DEM, Slope, Aspect, Lat, Lon, Soil texture & Our study \\
\hline
\end{tabular}

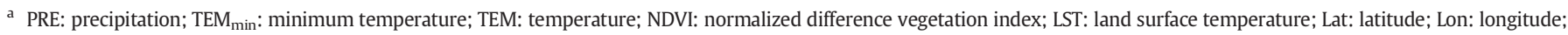
DOY: day of year; Tri: triangular feature space-based.

CCI SM was well reconstructed by the ANN model against the ground observations in the northwestern and eastern parts of China, with the CC more than 0.607 and the RMSE less than $0.074 \mathrm{~m}^{3} / \mathrm{m}^{3}$ during the growing season of 1991-2013. The gap-filled ESA CCI SM displayed a generally consistent spatial pattern compared with the ERA-Interim SM, GLADS-VIC SM, and GLADS-Noah SM, with an average CC of 0.670, 0.803, 0.838 and, respectively, and an average RMSE of $0.067,0.062$, and $0.051 \mathrm{~m}^{3} / \mathrm{m}^{3}$, respectively. Besides, the performance of the ANN model was similar to that of the RF model.

(2) The ANN model successfully reconstructed SM values with removed swaths. The average CC ranged from 0.801 to 0.911 , and the average RMSE varied from 0.035 to $0.037 \mathrm{~m}^{3} / \mathrm{m}^{3}$ in the ANN model, presenting better estimation accuracy than the OK model, with the average CC ranging from 0.500 to 0.905 , and the average RMSE fluctuating between 0.037 and $0.064 \mathrm{~m}^{3} / \mathrm{m}^{3}$. The ANN model simulation results were nearly unaffected by the removed swath's location in the ESA CCI SM image.

(3) The reconstructed SM of the ANN model presented a higher consistency in the sparsely vegetated region (SVR) than in the densely vegetated region (DVR) relative to the original ESA CCI $\mathrm{SM}$. The average CC and average RMSE of the ANN model in the SVR were 0.741 and $0.036 \mathrm{~m}^{3} / \mathrm{m}^{3}$, respectively, whereas those in the DVR were 0.636 and $0.032 \mathrm{~m}^{3} / \mathrm{m}^{3}$, respectively. Additionally, the gap-filling results of the ANN model were superior to those of the OK model in both two regions.

(4) Compared with the OK model, the sensitivity of the SM estimation accuracy of the ANN model against the percentage of data gaps (PDG) was relatively weak. The average CC and RMSE of the gapfilled ESA CCI SM based on the different PDG (10\%-90\%) ranged $0.811-0.923$ and $0.036-0.045 \mathrm{~m}^{3} / \mathrm{m}^{3}$, respectively, presenting better performance than that of the OK model. The OK model was characterized by the average CC ranging from 0.738 to 0.932 , and the average RMSE varying from 0.035 to $0.062 \mathrm{~m}^{3} / \mathrm{m}^{3}$. The estimation accuracy of ANN was significantly better than that of the OK model when the PDG was more than $40 \%$.

In summary, this study generated a spatially-complete and daily-continuous $0.25^{\circ} \times 0.25^{\circ} \mathrm{SM}$ dataset. The performance of the gapfilled method was systematically evaluated using three simulation scenarios, and the estimation results were validated. We hope that these results would be useful for daily spatiotemporal continuous monitoring of surface SM and could be applied to the fields of climate change, agricultural drought, and water resources management. In the future, we suggest introducing some key environment elements (e.g., vegetation cover type) in the ANN model so as to further improve the accuracy of SM simulation and conduct plenty of simulation experiments to discover the applicability of this method. Besides, we expect to use more suitable machine-learning algorithms (e.g., SVM, LSTM) to enhance the estimation accuracy of satellite-derived SM compared with the current ANN method.

\section{CRediT authorship contribution statement}

Linqi Zhang: Writing - original draft. Yi Liu: Methodology, Conceptualization, Writing - review \& editing. Liliang Ren: Project administration. Adriaan J. Teuling: Writing - review \& editing. Xiaoxiang Zhang: Supervision. Shanhu Jiang: Supervision. Xiaoli Yang: Supervision. Linyong Wei: Visualization, Software. Feng Zhong: Investigation. Lihong Zheng: Data curation.

\section{Declaration of competing interest}

The authors declare that they have no known competing financial interests or personal relationships that could have appeared to influence the work reported in this paper.

\section{Acknowledgments}

This study was supported by the National Key Research and Development Program approved by the Ministry of Science and Technology, the People's Republic of China, under Grant No. 2019YFC1510600 and 2016YFA0601504; the Fundamental Research Funds for the Central Universities under Grant No. B200204029; the National Natural Science Foundation of China under Grant No. 41807165; the Natural Science Foundation of Jiangsu Province, China under Grant No. BK20180512; and the Fundamental Research Funds for the Central Universities under Grant No. 2019B05214.

\section{References}

Abbaszadeh, P., Moradkhani, H., Zhan, X.W., 2019. Downscaling SMAP radiometer soil moisture over the CONUS using an ensemble learning method. Water Resour. Res. 55, 324-344. https://doi.org/10.1029/2018WR023354.

Albergel, C., de Rosnay, P., Gruhier, C., Muñoz-Sabater, J., Hasenauer, S., et al., 2012. Evaluation of remotely sensed and modelled soil moisture products using global groundbased in situ observations. Remote Sens. Environ. 118, 215-226. https://doi.org/ 10.1016/j.rse.2011.11.017.

Al-Yaari, A., Wigneron, J.P., Ducharne, A., Kerr, Y., De Rosnay, P., et al., 2014. Global scale evaluation of two satellite-based passive microwave soil moisture data sets (SMOS and AMSR-E) with respect to Land Data Assimilation System estimates. Remote Sens. Environ. 149, 181-195. https://doi.org/10.1016/j.rse.2014.04.006.

An, R., Zhang, L., Wang, Z., Quaye-Ballard, J.A., You, J., et al., 2016. Validation of the ESA CCI soil moisture product in China. Int. J. Appl. Earth Obs. Geoinf. 48, 28-36. https://doi. org/10.1016/j.jag.2015.09.009.

Barrett, E., Beaumont, M., Herschy, R., 1990. Satellite remote sensing for operational hydrology: present needs and future opportunities. Remote Sens. Rev. 4 (2), 451-466. https://doi.org/10.1080/02757259009532113.

Breiman, L., 2001. Random forests. Mach. Learn. 45 (1), 5-32. https://doi.org/10.1023/A: 1010933404324.

Cammalleri, C., Vogt, J.V., Bisselink, B., De Roo, A., 2017. Comparing soil moisture anomalies from multiple independent sources over different regions across the globe. Hydrol. Earth Syst. Sci. 21, 6329-6343. https://doi.org/10.5194/hess-21-6329-2017.

Chen, L.D., Huang, Z.L., Gong, J., Fu, B.J., Huang, Y.L., 2007. The effect of land cover/vegetation on soil water dynamic in the hilly area of the loess plateau, China. Catena 70 (2), 200-208. https://doi.org/10.1016/j.catena.2006.08.007.

Coulibaly, P., Evora, N., 2007. Comparison of neural network methods for infilling missing daily weather records. J. Hydrol. 341 (1-2), 27-41. https://doi.org/10.1016/j. jhydrol.2007.04.020.

Cui, Y., Long, D., Hong, Y., Zeng, C., Zhou, J., et al., 2016. Validation and reconstruction of FY-3B/MWRI soil moisture using an artificial neural network based on reconstructed MODIS optical products over the Tibetan Plateau. J. Hydrol. 543, 242-254. https://doi. org/10.1016/j.jhydrol.2016.10.005.

Cui, Y., Ma, S., Yao, Z., Chen, X., Luo, Z., et al., 2020. Developing a gap-filling algorithm using DNN for the Ts-VI triangle model to obtain temporally continuous daily actual evapotranspiration in an arid area of China. Remote Sens. 12, 1121. https://doi.org/ $10.3390 /$ rs12071121.

Cutler, A., Cutler, D.R., Stevens, J.R., 2011. Random forests. In: Zhang, C., Ma, Y. (Eds.), Ensemble Machine Learning: Methods and Applications. vol. 41. Springer Science+Business Media, Berlin, pp. 157-175. https://doi.org/10.1007/978-1-44199326-7_5. 
Dee, D.P., Uppala, S.M., Simmons, A.J., Berrisford, P., Poli, P., et al., 2011. The ERA-interim reanalysis: configuration and performance of the data assimilation system. Q. J. R. Meteorol. Soc. 137, 553-597. https://doi.org/10.1002/qj.828.

Dirmeyer, P.A., Guo, Z., Gao, X., 2004. Comparison, validation, and transferability of eight multiyear global soil wetness products. J. Hydrometeorol. 5, 1011-1033. https://doi. org/10.1175/JHM-388.1.

Dobriyal, P., Qureshi, A., Badola, R., Hussain, S.A., 2012. A review of the methods available for estimating soil moisture and its implications for water resource management. J. Hydrol. 458-459, 110-117. https://doi.org/10.1016/j.jhydrol.2012.06.021.

Dorigo, W., Wagner, W., Hohensinn, R., Hahn, S., Paulik, C., et al., 2011. The International Soil Moisture Network: a data hosting facility for global in situ soil moisture measurements. Hydrol. Earth Syst. Sci. 15 (5), 1675-1698. https://doi.org/10.5194/hessd-81609-2011.

Dorigo, W., Wagner, W., Albergel, C., Albrecht, F., Balsamo, G., et al., 2017. ESA CCI Soil Moisture for improved Earth system understanding: state-of-the art and future directions. Remote Sens. Environ. 203, 185-215. https://doi.org/10.1016/j.rse.2017.07.0017.

Fan, J.L., Scheuermann, A., Guyot, A., Baumgartl, T., Lockington, D.A., 2015. Quantifying spatiotemporal dynamics of root-zone soil water in a mixed forest on subtropical coastal sand dune using surface ERT and spatial TDR. J. Hydrol. 523, 475-488. https://doi.org/10.1016/j.jhydrol.2015.01.064.

Ford, T.W., Quiring, S.M., 2014. Comparison and application of multiple methods for temporal interpolation of daily soil moisture. Int. J. Climatol. 34 (8), 2604-2621. https:// doi.org/10.1002/joc.3862.

Gruhier, C., Rosnay, P.D., Hasenauer, S., Holmes, T.R.H., De Jeu, R.A.M., et al., 2010. Soil moisture active and passive microwave products: intercomparison and evaluation over a Sahelian site. Hydrol. Earth Syst. Sci. 14, 141-156. https://doi.org/10.5194/ hess-14-141-2010.

Heumann, B.W., 2011. Satellite remote sensing of mangrove forests: recent advances and future opportunities. Prog. Phys. Geogr. 35 (1), 87-108. https://doi.org/10.1177/ 0309133310385371.

Hillel, D., 1982. Introduction to Soil Physics. Academic Press.

Hutengs, C., Vohland, M., 2016. Downscaling land surface temperatures at regional scales with random forest regression. Remote Sens. Environ. 178, 127-141. https://doi.org/ 10.1016/j.rse.2016.03.006

Jing, W., Zhang, P., Zhao, X., 2018. Reconstructing monthly ECV global soil moisture with an improved spatial resolution. Water Resour. Manag. 32 (7), 2523-2537. https://doi. org/10.1007/s11269-018-1944-2.

Liang, S., Zhang, X., Xiao, Z., Cheng, J., Liu, Q., et al., 2013. Global Land Surface Satellite (GLASS) Products: Algorithms, Validation and Analysis. Springer, New York, NY, USA.

Liu, T., Juang, K.W., Lee, D.Y., 2006. Interpolating soil properties using kriging combined with categorical information of soil maps. Soil Sci. Soc. Am. J. 70 (4), 1200-1209. https://doi.org/10.2136/sssaj2005.0126.

Liu, Y., Parinussa, R.M., Dorigo, W.A., De Jeu, R.A.M., Wagner, W., et al., 2011. Developing an improved soil moisture dataset by blending passive and active microwave satellite-based retrievals. Hydrol. Earth Syst. Sci. 15, 425-436. https://doi.org/ 10.5194/hess-15-425-2011.

Liu, Y., Yao, L., Jing, W., Di, L., Yang, J., Li, Y., 2020a. Comparison of two satellite-based soil moisture reconstruction algorithms: a case study in the state of Oklahoma, USA. J. Hydrol. 590, 125406. https://doi.org/10.1016/j.jhydrol.2020.125406.

Liu, Y., Zhu, Y., Zhang, L., Ren, L., Yuan, F., et al., 2020b. Flash droughts characterization over China: from a perspective of the rapid intensification rate. Sci. Total Environ. 704 (20), 135373. https://doi.org/10.1016/j.scitotenv.2019.135373.

Llamas, R.M., Guevara, M., Rorabaugh, D., Taufer, M., Vargas, R., 2020. Spatial gap-filling of ESA CCI satellite-derived soil moisture based on geostatistical techniques and multiple regression. Remote Sens. 12 (4), 665. https://doi.org/10.3390/rs12040665.

Loew, A., Ludwig, R., Mauser, W., 2006. Derivation of surface soil moisture from envisat asar wide swath and image mode data in agricultural areas. IEEE Trans. Geosci. Remote Sens. 44 (4), 889-899. https://doi.org/10.1109/TGRS.2005.863858.

Long, D., Bai, L., Yan, L., Zhang, C., Yang, W., et al., 2019. Generation of spatially complete and daily continuous surface soil moisture of high spatial resolution. Remote Sens. Environ. 233, 11364. https://doi.org/10.1016/j.rse.2019.111364.

Mao, H., Kathuria, D., Duffield, N., Mohanty, B.P., 2019. Gap filling of high-resolution soil moisture for SMAP/Sentinel-1: a two-layer machine learning-based framework. Water Resour. Res. 55, 6986-7009. https://doi.org/10.1029/2019WR024902.

Mariethoz, G., McCabe, M.F., Renard, P., 2012. Spatiotemporal reconstruction of gaps in multivariate fields using the direct sampling approach. Water Resour. Res. 48, W10507. https://doi.org/10.1029/2012WR012115.

Nachtergaele, F.O., van Velthuizen, H., Verelst, L., Batjes, N.H., Dijkshoorn, J.A., et al., 2009. Harmonized world soil database (version 1.1). Food and Agriculture Organization of the UN (FAO); International Inst. for Applied Systems Analysis (IIASA); ISRIC-World Soil Information; Inst. of Soil Science-Chinese Academic of Sciences (ISS-CAS); ECJoint Research Centre (JRC): Laxenburg, Austria.

Ng, W., Panu, U., Lennox, W., 2009. Comparative studies in problems of missing extreme daily streamflow records. J. Hydrol. Eng. 14 (1), 91-100. https://doi.org/10.1061/ (ASCE)1084-0699(2009)14:1(91).

Ngunyen, H.H., Kim, H., Choi, M., 2017. Evaluation of the soil water content using cosmic-ray neutron probe in a heterogeneous monsoon climate-dominated region. Adv. Water Resour. 2017 (108), 125-138. https://doi.org/10.1016/j.advwatres.2017.07.020.

Njoku, E.G., Jackson, T.J., Lakshmi, V., Chan, T.K., Nghiem, S.V., 2003. Soil moisture retrieval from AMSR-E. IEEE Trans. Geosci. Remote Sens. 41 (2), 215-229. https://doi.org/ 10.1109/TGRS.2002.808243.

Ochsner, T.E., Cosh, M.H., Cuenca, R.H., Dorigo, W.A., Draper, C.S., et al., 2013. State of the art in large-scale soil moisture monitoring. Soil Sci. Soc. Am. J. 77 (6), 1888-1919. https://doi.org/10.2136/sssaj2013.03.0093.
Park, S., Im, J., Park, S., Rhee, J., 2017. Drought monitoring using high resolution soil moisture through multi-sensor satellite data fusion over the Korean peninsula. Agric. For Meteorol. 237-238, 257-269. https://doi.org/10.1016/j.agrformet.2017.02.022.

Peng, J., Loew, A., Merlin, O., Verhoest, N.E.C., 2017. A review of spatial downscaling of satellite remotely sensed soil moisture. Rev. Geophys. 55, 341-366. https://doi.org/ 10.1002/2016RG000543.

Pollen-Bankhead, N., Simon, A., 2010. Hydrologic and hydraulic effects of riparian root networks on streambank stability: is mechanical root-reinforcement the whole story? Geomorphology. 116 (3), 353-362. https://doi.org/10.1016/j.geomorph.2009.11.013.

Quiring, S.M., Ford, T.W., Wang, J.K., Khong, A., Harris, E., et al., 2016. The North American soil moisture database: development and applications. Bull. Am. Meteorol. Soc. 97, 1441-1459. https://doi.org/10.1175/BAMS-D-13-00263.1.

Rahmati, O., Falah, F., Dayal, K.S., Deo, R.C., Mohammadi, F., et al., 2020. Machine learning approaches for spatial modeling of agricultural droughts in the south-east region of Queensland Australia. Sci. Total Environ. 699, 134230. https://doi.org/10.1016/j. scitotenv.2019.134230.

Raoult, N., Delorme, B., Ottlé, C., Peylin, P., Bastrikov, V., et al., 2018. Confronting soil moisture dynamics from the ORCHIDEE land surface model with the ESA-CCI product: perspectives for data assimilation. Remote Sens. 10, 1786. https://doi.org/10.3390/ rs10111786.

Robock, A., Vinnikov, K.Y., Srinivasan, G., Entin, J.K., Hollinger, S.E., et al., 2000. The global soil moisture data bank. Bull. Am. Meteorol. Soc. 81, 1281-1299. https://doi.org/ 10.1175/1520-0477(2000)0812.3.CO;2.

Rodell, M., Houser, P.R., Jambor, U., Gottschalck, J., Mitchell, K., et al., 2004. The global land data assimilation system. Bull. Am. Meteorol. Soc. 85 (3), 381-394. https://doi.org/ 10.1175/BAMS-85-3-381.

Rumelhart, D.E., Hinton, G.E., Williams, R.J., 1986. Learning representations by backpropagating errors. Nature. 323 (6088), 533-536. https://doi.org/10.1038/ 323533a0.

Saxton, K.E., Rawls, W.J., 2006. Soil water characteristic estimates by texture and organic matter for hydrologic solutions. Soil Sci. Soc. Am. J. 70 (5), 1569-1578. https://doi org $/ 10.2136 /$ sssaj2005.0117.

Schneider, T., 2001. Analysis of incomplete climate data: estimation of mean values and covariance matrices and imputation of missing values. J. Clim. 14, 853-871. https:// doi.org/10.1175/1520-0442(2001)0142.0.CO;2.

Sheffield, J., Wood, E.F., 2008. Global trends and variability in soil moisture and drought characteristics, 1950-2000, from observation-driven simulations of the terrestrial hydrologic cycle. J. Clim. 21 (3), 432-458. https://doi.org/10.1175/2007JCLI1822.1.

Sun, Z., Long, D., Yang, W., Li, X., Pan, Y., 2020. Reconstruction of GRACE data on changes in total water storage over the global land surface and 60 basins. Water Resour. Res. 55, e2019WR026250. https://doi.org/10.1029/2019WR026250.

Teuling, A.J., 2018. A hot future for European droughts. Nat. Clim. Chang. 8, 360-369. https://doi.org/10.1038/s41558-018-0154-5.

Turlapaty, A.C., Younan, N.H., Anantharaj, V.G., 2011. Interpolation of missing values in AMSR-E soil moisture data using modified SSA. IEEE Geosci. Remote Sens. Lett. 8 (2), 322-325. https://doi.org/10.1109/LGRS.2010.2071852.

Wagner, W., Pathe, C., Doubkova, M., Sabel, D., Bartsch, A., et al., 2008. Temporal stability of soil moisture and radar backscatter observed by the Advanced Synthetic Aperture Radar (ASAR). Sensors. 8 (2), 1174-1197. https://doi.org/10.3390/s80201174

Wagner, W., Dorigo, W., de Jeu, R., Fernandez, D., Benveniste, J., et al., 2012. Fusion of active and passive microwave observations to create an essential climate variable data record on soil moisture. ISPRS Ann. Photogramm. Remote Sens. Spat. Inf. Sci. 1-7, 315-321. https://doi.org/10.5194/isprsannals-I-7-315-2012.

Wanders, N., Karssenberg, D., de Roo, A., de Jong, S.M., Bierkens, M.F.P., 2014. The suitability of remotely sensed soil moisture for improving operational flood forecasting. Hydrol. Earth Syst. Sci. 18 (6), 2343-2357. https://doi.org/10.5194/hess-18-23432014.

Wang, G., Garcia, D., Liu, Y., de Jeu, R., Dolman, A.J., 2012. A three-dimensional gap filling method for large geophysical datasets: application to global satellite soil moisture observations. Environ. Model. Softw. 30, 139-142. https://doi.org/10.1016/j. envsoft.2011.10.015.

Wang L, Wang P. Liang S, Qi, X, Li, L et al, 2019. Monitoring maize growth conditions by training a BP neural network with remotely sensed vegetation temperature condition index and leaf area index. Comput. Electron. Agric. 160, 82-90. https://doi.org/ 10.1016/j.compag.2019.03.017.

Wei, L., Jiang, S., Ren, L., Yuan, F., Zhang, L., 2019. Performance of two long-term satellitebased and GPCC 8.0 precipitation products for drought monitoring over the Yellow River Basin in China. Sustainability 11 (18). https://doi.org/10.3390/su11184969.

Xiao, Z., Jiang, L., Zhu, Z., Wang, J., Du, J., 2016. Spatially and temporally complete satellite soil moisture data based on a data assimilation method. Remote Sens. https://doi.org/ $10.3390 / \mathrm{rs} 8010049$

Xie, X. Li, A., Jin, H., Tan, J., Wang, C., et al., 2019. Assessment of five satellite-derived LA datasets for GPP estimations through ecosystem models. Sci. Total Environ. 690, 1120-1130. https://doi.org/10.1016/j.scitotenv.2019.06.516.

Xing, C., Chen, N., Zhang, X., Gong, J., 2017. A machine learning based reconstruction method for satellite remote sensing of soil moisture images with in situ observations. Remote Sens. 9, 484. https://doi.org/10.3390/rs9050484.

Yuan, X., Ma, Z., Pan, M., Shi, C., 2015. Microwave remote sensing of short-term droughts during crop growing seasons. Geophys. Res. Lett. 42 (11), 4394-4401. https://doi.org/ 10.1002/2015GL064125.

Yuan, Q., Shen, H., Li, T., Li, Z., Li, S., et al., 2020. Deep learning in environmental remote sensing: achievements and challenges. Remote Sens. Environ. 241, 111716. https:// doi.org/10.1016/j.rse.2020.111716.

Zeng, J., Li, Z., Chen, Q., Bi, H., Qiu, J., et al., 2015. Evaluation of remotely sensed and reanalysis soil moisture products over the Tibetan Plateau using in-situ observations. Remote Sens. Environ. 163, 91-110. https://doi.org/10.1016/j.rse.2015.03.008. 
Zhang, Y., Wu, L., 2009. Stock market prediction of S\&P 500 via combination of improved BCO approach and BP neural network. Expert Syst. Appl. 36 (5), 8849-8854. https:// doi.org/10.1016/j.eswa.2008.11.028.

Zhang, L., Liu, Y., Ren, L., Jiang, S., Yang, X., et al., 2019. Drought monitoring and evaluation by ESA CCI soil moisture products over the Yellow River Basin. IEEE J. Sel. Top. Appl. Earth Observ. Remote Sens. 12 (9), 3376-3386. https://doi.org/10.1109/ JSTARS.2019.2934732
Zhu, Z., Bi, J., Pan, Y., Ganguly, S., Anav, A., et al., 2013. Global data sets of vegetation leaf area index (LAI)3g and fraction of photosynthetically active radiation (FPAR)3g derived from global inventory modeling and mapping studies (GIMMS) normalized difference vegetation index (NDVI3g) for the period 1981 to 2011. Remote Sens. 5 (2), 927-948. https://doi.org/10.3390/rs5020927. 